\title{
Policy Characteristics and Stakeholder Returns in Participating Life Insurance: Which Contracts Can Lead to a Win-Win?*
}

\author{
Charbel Mirza and Joël Wagner ${ }^{\dagger}$
}

\begin{abstract}
Participating life insurance contracts and pension plans often include a return guarantee and participation in the surplus of the institution's result. The final account value in such contracts depends on the investment policy driven by solvency requirements, as well as on the level of market returns, the guarantee and the participation rates. Using a contingent claim model for such contracts, we assume a competitive market with minimum solvency requirements similar to Solvency II. We consider solvency requirements on maturity and one-year time horizons, as well as contracts with single and periodic premium payments. Through numerical analyses, we link the expected returns for equity holders and policyholders in various situations. Using the return on equity and policyholder internal rate of return along with utility measures, we assess which contract settings optimize the return compromise for both stakeholders in a low-interest-rate environment. Our results extend the academic literature by building on the work by Schmeiser and Wagner (2015) and are relevant for practitioners, given the current financial market environment and difficulties in insurance-linked savings plans with guarantees.
\end{abstract}

Key words life insurance products $\cdot$ interest rate guarantee $\cdot$ policyholder participation return on investment

\section{Introduction}

Defined-contributions-funded pension plans in many old-age provision systems, as well as the traditional with-profits endowment insurance policies sold in German-speaking countries include interest rate guarantees and profit participation for the insureds. The guaranteed interest is based on the value of the savings and credited on a yearly basis to the policyholders' accounts. In life insurance policies, the interest rate for this "cliquet-style" guarantee is typically set for the whole contract duration at inception; in pension plans, this rate is adapted periodically and called "technical interest". The profit participation is calculated as a share of the pension scheme or insurance company surplus. Technical rates for reserving and profit participation are regulated by supervisory authorities and/or the government. For example, authorities typically set a maximum value for the technical interest rate to limit the solvency hazards for providers.

\footnotetext{
${ }^{*}$ This is a post-peer-review, pre-copyedit version of an article published in European Actuarial Journal. The final authenticated version is available online at: https://doi.org/10.1007/s13385-018-0179-1.

${ }^{\dagger}$ Charbel Mirza (charbel.mirza@unil.ch) and Joël Wagner (joel.wagner@unil.ch) are with the Department of Actuarial Science, Faculty of Business and Economics, University of Lausanne. The second author is also with the Swiss Finance Institute, Lausanne, Switzerland.
} 
Furthermore, there is often a minimum value for profit participation to grant the insureds adequate participation in their provider's excess return. ${ }^{1}$ These traditional life insurance products are very popular among customers; products with guarantees account for approximately 75 percent of the market in Germany (International Association of Insurance Supervisors, 2016, Table 1).

Participating life insurance contracts and funded pension plans feature a combination of the following components: yearly interest credited to the savings account, participation in the insurer's profit, and a high level of safety through imposed solvency requirements. To limit the risk exposure for companies offering interest rate guarantees, the technical interest rate is limited (see Grosen and Jorgensen, 2002, and Eling and Holder, 2013a, for an overview). ${ }^{2}$ In fact, given that the rates applied mostly do not need approval by the financial market authorities, the latter prescribe certain special requirements, including those for technical interest rates and surrender values. In the European Union (E.U.) and Switzerland, technical interest rates are limited to the 60 percent 10-year rolling average return of local government bonds (see European Union, 1992, Art. 18, European Union, 2002, Art. 20, and Swiss Federal Council, 2005, Art. 121). We illustrate the evolution of the situation in Switzerland in Figure 1. The return of 10-year Swiss government bonds decreased from approximately $6 \%$ in the early 1990s to negative yields in 2015. We observe that the adaptation of the maximum technical interest has been relatively slow. In January 2016, the rate was set to 0.75 percent in Switzerland; in 2015 it was 1.25 percent in Germany (German Federal Ministry of Justice, 2014b). In the past, given intuitive sales arguments and naive contract valuation (i.e., that "contracts with higher guarantees are better"), most market players offered the maximum allowed technical rate as guarantee to their individual customers. This led Schmeiser and Wagner (2015) to investigate raising the optimal level for the upper boundary rate set by the regulator (also see below). The current development in the financial markets with lower interest rates accompanied by relatively higher return volatility makes guarantees more difficult for insurers to manage. Currently, most companies have stopped offering the maximum allowed, and they often offer guarantees below the nominal value of the customer savings premiums. Some firms have even stopped offering products with guarantees or have sold their traditional business to investors (see, e.g., Baloise Group, 2015, in Germany).

The holders of traditional life insurance policies participate in the insurer's surplus, an important component of the final payoff to policyholders. The minimum surplus participation rate in German life insurance contracts is defined at 90\% (German Federal Ministry of Justice, 2014a). This also holds for Swiss collective life insurance (see Federal Assembly of the Swiss Confederation, 2004, Art. 37, and Swiss Federal Council, 2005, Art. 147). This rate, the socalled "legal quote," has been a subject of discussion in recent years (Killer, 2015). Furthermore, to ensure an adequate safety level for insurance companies, regulatory authorities require a certain equity level for firms to operate. Their solvency level is monitored on a yearly basis. The Swiss Solvency Test (SST), which has been in force since 2011 (see Swiss Financial Market

\footnotetext{
${ }^{1}$ In this paper, we focus on the products offered in Switzerland and Germany, where participating life insurance with guarantees is very popular. In Swiss collective life insurance contracts, the interest rate defined by the authorities is to be followed exactly. The lower bound for policyholders' profit participation holds in German participating life insurance contracts and in Swiss collective life insurance.

${ }^{2} \mathrm{~A}$ short review of insurer defaults linked to interest rate guarantees is provided, for example, in the Introduction in Schmeiser and Wagner (2015). The references cited therein (see their Footnote 2) give more detailed information. Following the introduction of the Solvency II regulation in the European Union, some of the conditions, in particular those linked to the asset allocation have been relaxed and replaced by a more comprehensive risk assessment, see, e.g., Braun et al. (2018).
} 


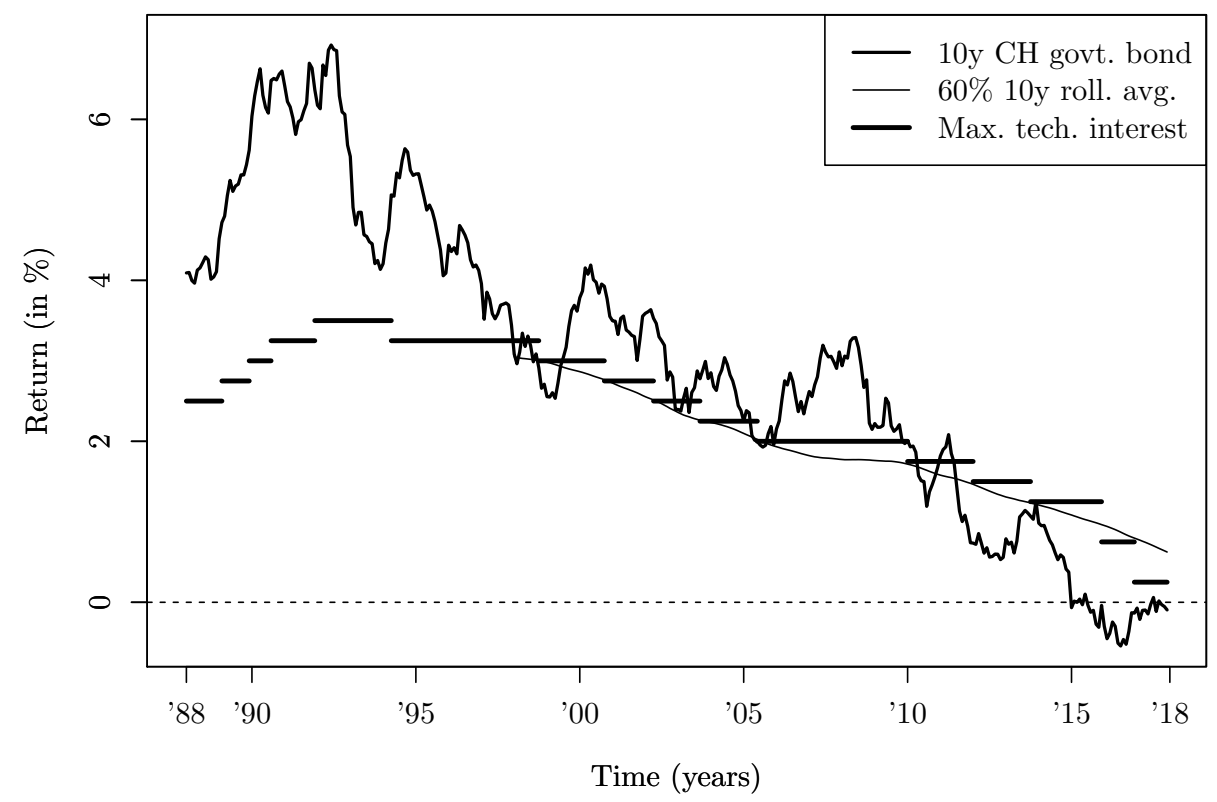

Figure 1: Illustration of the historical 10-year Swiss Government Bond yields (in \%) from 1988 to 2017 and the maximum technical interest rate defined by the $60 \%$ of the 10 -year rolling average on the bond's return.

Note: Data from FINMA (see www.finma.ch/en/supervision/insurers/sector-specific-tools/individuallife-insurance) and Swiss National Bank (see data.snb.ch/en).

Supervisory Authority, FINMA, and, e.g., Eling et al., 2008, for a discussion), is considered equivalent (European Commission, 2015) to the Solvency II framework of the E.U. enforced since January 2016. Through its value-at-risk approach, the latter explicitly requires that risk capital maintain the annual probability of ruin lower than 0.5 percent (see, European Union, 2009, Art. 64, European Union, 2014).

Our research focus is as follows. Building on Schmeiser and Wagner (2015), we aim to analyze the link between the main insurance contract features - the levels of interest rate guarantee and policyholder participation - and equity holder and policyholder returns. In fact, under a competitive market assumption and solvency requirements, both contract features entail a unique optimal solution for the required initial equity and asset allocation strategy. We compare the results obtained in the earlier paper, assuming upfront premiums and default at maturity to situations with periodic monitoring. The model framework that we use is similar to the one introduced by Schmeiser and Wagner (2015) and a recent working paper by Braun et al. (2015). Unlike the first study, which focuses on the maximum technical interest rate fixed by the regulator, we consider both contract parameters and guarantee and participation rates and analyze their interaction. We also introduce two different cases, allowing us to compare contracts with single upfront premiums, with default at maturity, with overall ruin probability, and with a single investment decision on one hand and with periodic premiums, with yearly control of defaults, with annual safety level monitoring and annual adaptation of asset allocation on the other. Braun et al. (2015) also build on the model framework introduced by Schmeiser and Wagner (2015). They extend the earlier analysis by including regular premiums, death and surrender payouts, stochastic interest rates and early defaults. In contrast to the two above 
studies, we consider the effective rate of return on the policyholders' savings premiums beyond the utility assessment, focus on the participation rates offered to clients and consider the equity holder's position not only by requiring fairly valued contracts but also by analyzing the expected return on the invested equity.

Our study, as well as the two works cited above, are part of the literature on participating life insurance contracts. Given the model framework used in the analyses, the stream of literature includes works focusing on the fair valuation of insurance liabilities (e.g., Grosen and Jorgensen, 2000, Gatzert and Kling, 2007), on the contingent claim approach (e.g., Briys and de Varenne, 1997, Grosen and Jorgensen, 2002), and on the value creation for customers (e.g., Gatzert et al., 2012). A numerical analysis of the interaction of guarantees, surplus distribution and asset allocation can be found in Kling et al. (2007a) and Kling et al. (2007b). The recent work by Eling and Holder (2013b) analyzes alternative guarantee designs. We refer the reader to the references contained in the above papers for a larger overview.

Our three main results are as follows: (1) we confirm the study by Schmeiser and Wagner (2015) concluding that lower guarantees can lead to higher values for customers and extend their model including periodic premiums, yearly solvency restrictions and asset allocation; (2) we observe that, in the set of fairly priced contracts, the interaction of guarantees, participation, solvency considerations and asset allocation must be carefully analyzed and handled in the development of new product offerings; (3) we conclude that contract parameterizations that offer constant returns on equity to equity holders while preserving (or even increasing) average return rates for policyholders are available. More specifically, we find that lower policy interest rate guarantees and lower participation rates offered to customers lead, on average, to higher customer returns and to higher return on equity (see also the conclusion detailed in Section 5). Our results can be applied to individual life, collective life and pension insurance featuring guarantees and participation components.

The remainder of this article is organized as follows. In Section 2, we outline the model framework. We introduce the insurer investment and policyholder accounts and the payoffs under default risk, and we describe the market constraints and regulatory requirements considered. We also define how we measure the returns and the utility for both equity holders and policyholders. In Section 3, we describe the model parameterization. Section 4 reports the results obtained in our models and provides detailed sensitivity analyses. We conclude in Section 5. The Appendix gives detailed notes on the model implementation and provides further results.

\section{Model Framework}

The guaranteed interest, the underlying investment and policyholder participation in the surplus are closely linked to the savings component of life insurance policies. Thus, we follow the exposition of Schmeiser and Wagner (2015) and consider a basic life insurance model, putting our focus on policyholders' savings accounts. We focus on the savings premium, that is, the premium amount available for investment after deducting transaction costs and the term life premium (we suppose that mortality risk is diversified).

Because we want to consider default risk explicitly in our model, we use the contingent claim model framework first introduced by Doherty and Garven (1986) and Briys and de Varenne (1997). In their setup, insolvency risk is considered at the end of the contract (see our model A). This model is justifiable as long as payouts occur only at the maturity of the contract. In the second model, we introduce (see model B) solvency testing and shortfalls on a yearly basis, as 
it is done in current solvency frameworks (see also Grosen and Jorgensen, 2002, Bernard et al., 2005, and, more recently, Braun et al., 2015). This model setup will allow us to monitor solvency levels on a yearly basis (and allow for defaults, i.e., no negative equity capital allowed) and to adapt asset allocation. Following the previous models, we consider complete and arbitrage-free capital markets. Finally, we require risk-adequate positions for equity holders and policyholders and assume solvency regulation, defining an upper bound for the ruin probability (at maturity in model A and on a yearly basis in model B).

\subsection{Insurer's Investment and Policyholders' Accounts}

In both models, we consider that the policyholder pays a stream of previously known savings premiums $\Pi_{t}, t=0, \ldots, T-1$, at the beginning of each year during the whole contract duration $T$. In model (A), we assume a single upfront premium can be deduced by setting $\Pi_{t}=0$ for $t=1, \ldots, T-1$. At contract inception in $t=0$, the insurance company investors provide an amount of equity capital that we denote with $E_{0}$. The initial insurer's assets $A_{0}$ correspond to the equity capital $E_{0}$. At the beginning of every period, the savings premium $\Pi_{t}$ is added to company assets, and the whole amount is invested in the capital market, leading to a stochastic value of assets $A_{t}$ for $t=1, \ldots T$.

We follow the two-asset model introduced in Merton (1969) and assume that the assets $A_{t}$ at times $t=0, \ldots, T-1$, are invested in two asset classes. For the first class (I), we consider a risk-free asset with returns $r_{t}^{(\mathrm{I})}$ in the periods $t=1, \ldots, T$. For the second class (II), we consider a risky asset with returns $r_{t}^{(\mathrm{II})}, t=1, \ldots, T$. The portfolio return is given by a mix of two asset returns as follows: in each period $t=1, \ldots, T$, we assume that a share $\gamma_{t}$ of the assets $A_{t-1}$ available at the beginning of the periods is invested in class (I) and that the remaining part $\left(1-\gamma_{t}\right)$ is invested in class (II). Because we do not consider interim assessments in the model (A), we have $\gamma_{t}=\gamma$, where $\gamma$ is fixed at the beginning of the contract and for the whole duration. In model (B), $\gamma_{t}$ will be reviewed yearly on the basis of previous asset performance, the accruing asset value from additional premium payments and with respect to the limit on the probability of ruin. We show how to calculate $\gamma_{t}$ for model (B) in Section 3. In both cases (A) and $(\mathrm{B})$, the periodic portfolio return in periods $t=1, \ldots, T$ can be written as

$$
R_{t}=\gamma_{t} e^{r_{t}^{(\mathrm{I})}}+\left(1-\gamma_{t}\right) e^{r_{t}^{(\mathrm{II})}}-1
$$

and, combining the asset returns and the premium payments, the value of the portfolio assets in times $t=1, \ldots, T$ is given by

$$
A_{t}=\left(A_{t-1}+\Pi_{t-1}\right) \cdot\left(1+R_{t}\right) .
$$

Following Schmeiser and Wagner (2015), we suppose that the risk-free asset has a constant return $r_{\mathrm{f}}$ over the whole period, i.e., $r_{t}^{(\mathrm{I})}=r_{\mathrm{f}}$. We consider the returns from the risky asset (II) to be normally distributed. We set $W_{t}^{\mathbb{P}}, t=0, \ldots, T$ a standard geometric Brownian motion on a probability space $(\Omega, \Phi, \mathbb{P})$ with $\Phi_{t}, t=0, \ldots, T$ the generated filtration of the Brownian motion and $\mathbb{P}$ the real-world measure. The stochastic process is determined by a given drift $\mu_{\mathrm{B}}$ and volatility $\sigma_{\mathrm{B}}$, which gives us the return $r_{t}^{(\mathrm{II})}=\mu_{\mathrm{B}}-\sigma_{\mathrm{B}}^{2} / 2+\sigma_{\mathrm{B}}\left(W_{t}^{\mathbb{P}}-W_{t-1}^{\mathbb{P}}\right)$, for $t=1, \ldots, T$. This leads us to the recursive formula defining the evolution of the insurer's asset portfolio at times $t=1, \ldots, T$,

$$
A_{t}=\left(A_{t-1}+\Pi_{t-1}\right) \cdot\left[\gamma_{t} e^{r_{\mathrm{f}}}+\left(1-\gamma_{t}\right) e^{\mu_{\mathrm{B}}-\sigma_{\mathrm{B}}^{2} / 2+\sigma_{\mathrm{B}}\left(W_{t}^{\mathbb{P}}-W_{t-1}^{\mathbb{P}}\right)}\right]
$$


with initial condition $A_{0}=E_{0}$ and given savings premiums $\Pi_{t}, t=0, \ldots, T-1$. We call $\left[1+R_{t}^{\mathbb{P}}\right]$ the expression in brackets [.] in Equation (3), i.e.,

$$
R_{t}^{\mathbb{P}}=\gamma_{t} e^{r_{\mathrm{f}}}+\left(1-\gamma_{t}\right) e^{\mu_{\mathrm{B}}-\sigma_{\mathrm{B}}^{2} / 2+\sigma_{\mathrm{B}}\left(W_{t}^{\mathbb{P}}-W_{t-1}^{\mathbb{P}}\right)}-1 .
$$

Thus, the actual asset value is calculated from the risk-free and risky investment returns, given the portfolio asset allocation defined through $\gamma_{t}$.

The policyholder savings account value $P_{t}, t=0, \ldots, T$, i.e., the insurer's liabilities, evolves as follows. The premiums $\Pi_{t}$ are added to the savings account. The insurer yearly guarantees a minimum interest rate of $g$ on the account value over the whole contract duration. Furthermore, the policyholder participates at a rate $\alpha$ in the insurer's investment returns $R_{t}^{\mathbb{P}}{ }^{3}$ At the end of the period the savings account is credited with the greater rate between $g$ and $\alpha R_{t}^{\mathbb{P}}$. Hence, the evolution of the policyholder account $P_{t}, t=1, \ldots, T$ is given by

$$
P_{t}=\left(P_{t-1}+\Pi_{t-1}\right) \cdot\left[1+\max \left(g, \alpha R_{t}^{\mathbb{P}}\right)\right]
$$

where $P_{0}=0$. In the case where the company remains solvent during the whole contract duration, the policyholder gets the payout $P_{T}$.

\subsection{Policyholder and Investor Payoffs under Default Risk}

Model (A). In Schmeiser and Wagner (2015) and our model (A), the main concern is the solvency at time $t=T$. In fact, we consider no payouts until $T$, and shortfall happens only at maturity. The insurer is said to be solvent at time $T$ if the value of the insurance assets $A_{T}$ is higher than the value of the liabilities $P_{T}$. The cost of the insolvency $D_{T}$ or the default put option (cf. Doherty and Garven, 1986; Butsic, 1994) is the value of the deficit of the company when bankruptcy occurs. We can write out

$$
D_{T}=\left(P_{T}-A_{T}\right)^{+},
$$

where $(\cdot)^{+}$stands for $\max (\cdot ; 0) . D_{T}=0$ when the assets $A_{T}$ exceed the liabilities $P_{T}$. If the assets are insufficient to cover the liabilities, $D_{T}$ yields the difference $P_{T}-A_{T}>0$. By allowing for defaults at contract maturity $T$, the final policyholder payoff $L_{T}$ is

$$
L_{T}=P_{T}-D_{T}=P_{T}-\left(P_{T}-A_{T}\right)^{+} .
$$

The equity holder stake $E_{T}$ at time $T$ is given by the remaining assets after the policyholder has been paid out, i.e.,

$$
E_{T}=A_{T}-L_{T}=\left(A_{T}-P_{T}\right)^{+} .
$$

Model (B). In reality, solvency regulation requires insurance companies to control safety levels on a yearly basis. Thus, monitoring possible defaults and considering the consequences when business activity stops extends the model (A). If bankruptcy occurs at some time $t^{*}>0$, we assume that the contract is stopped and the policyholder is paid out the available funds.

\footnotetext{
${ }^{3}$ In this simple setup, following Schmeiser and Wagner (2015), we directly link the investment return to the return credited to the policyholder account. Since in practice smoothing mechanisms for the surplus distribution are in place, our results overestimate the asset volatility. We show that our conceptual findings remain valid by comparing our results with simulations using a much lower asset volatility (compare the results from Tables 4 and 5 in Section 4.1 with Tables 8 and 9 reported in the Appendix).
} 
Furthermore, we suppose that the payoff in $t^{*}$ is then invested at the risk-free rate $r_{\mathrm{f}}$ until time $T .{ }^{4}$ In analogy to the notations above, the cost of the insurer insolvency at time $t^{*}$ is defined by $D_{t}^{*}$,

$$
D_{t^{*}}=P_{t^{*}}-A_{t^{*}}>0
$$

While taking into account the amount of losses when insolvency occurs at $t^{*}$, the amount due to the policyholder $L_{T}$ at maturity $T$ is given by

$$
L_{T}= \begin{cases}\left(P_{t^{*}}-D_{t^{*}}\right) e^{r_{\mathrm{f}}\left(T-t^{*}\right)} & \text { when default occurs at time } t^{*}>0 \\ P_{T} & \text { when no default occurs. }\end{cases}
$$

The equity holder stake $E_{T}$ at maturity $T$ is given through the formula in Equation (8).

\subsection{Market Constraints and Regulatory Requirements}

In the following, we formally introduce our assumptions about the market and the regulatory environment. The contracts offered have consequences for the insurer's asset allocation. Atop the risk-neutral valuation used for pricing purposes, we consider return and utility measures used by the equity holders and policyholders to assess the contract.

\section{Pricing in a Competitive Market}

Under the assumption of an arbitrage-free capital market, we evaluate the equity holder and policyholder claims under the $\mathbb{Q}$-measure using the concept of risk-neutral valuation. Under $\mathbb{Q}$, the evolution of the insurer's asset portfolio $A_{t}, t=1, \ldots, T$ is given by (compare with Equation (3)):

$$
A_{t}=\left(A_{t-1}+\Pi_{t-1}\right) \cdot\left[\gamma_{t} e^{r_{\mathrm{f}}}+\left(1-\gamma_{t}\right) e^{r_{\mathrm{f}}-\sigma_{\mathrm{B}}^{2} / 2+\sigma_{\mathrm{B}}\left(W_{t}^{\mathbb{Q}}-W_{t-1}^{\mathbb{Q}}\right)}\right] .
$$

Here, $W_{t}^{\mathbb{Q}}$ is a $\mathbb{Q}$-Brownian motion. Under the risk-neutral measure, the values of the policyholder and equity holder stakes at time $t=0$ are given by $\mathbb{E}_{0}^{\mathbb{Q}}\left[L_{T}\right]=\mathbb{E}^{\mathbb{Q}}\left[e^{-r_{\mathrm{f}} T} \cdot L_{T}\right]$ and $\mathbb{E}_{0}^{\mathbb{Q}}\left[E_{T}\right]=\mathbb{E}^{\mathbb{Q}}\left[e^{-r_{\mathrm{f}} T} \cdot E_{T}\right]$, respectively, where $\mathbb{E}[\cdot]$ denotes the expected value and $L_{T}$ and $E_{T}$ are defined through Equations (7) and (8) (in model A) and (10) and (8) (in model B).

The competitive market assumption implies risk-adequate or fair pricing. That is, at the beginning of the contract and for the policyholder, the present value of the payoff equals the present value of the premium payments. For the equity holder, risk-adequate returns on the capital are generated and, thus, an appropriate return is ensured. Hence, the net present value of the equity holder and policyholder payoff must equal zero, i.e., we have the equity holder condition

$$
\mathbb{E}_{0}^{\mathbb{Q}}\left[E_{T}\right]-E_{0}=0
$$

and the policyholder condition

$$
\mathbb{E}_{0}^{\mathbb{Q}}\left[L_{T}\right]-\sum_{t=0}^{T-1}\left(e^{-r_{\mathrm{f}} t} \cdot \Pi_{t}\right)=0 .
$$

Both conditions are equivalent because no arbitrage possibilities are assumed. In the case of a

\footnotetext{
${ }^{4}$ We do not consider that a guarantee fund will step in and ensure the interest $g$, see, e.g., Rymaszewski et al. (2012); Schmeiser and Wagner (2013).
} 
single upfront premium (model A), Equation (13) reduces to $\mathbb{E}_{0}^{\mathbb{Q}}\left[L_{T}\right]-\Pi_{0}=0$ (cf. Schmeiser and Wagner, 2015).

\section{Solvency Requirement}

Solvency regulation in Europe requires insurers to maintain a certain safety level. This level is often expressed as an upper bound on the ruin probability.

Model (A). Because payouts are not made before the end of the contract at time $T$, we consider default risk only at the contract's maturity (see Schmeiser and Wagner, 2015). Following the definition of shortfall in Section 2.2, we evaluate the risk on ruin under the realworld measure $\mathbb{P}$ and introduce the solvency rule in $T$, requiring that the default probability $R_{T}$ is bounded from above by

$$
R_{T}=\operatorname{Pr}\left(A_{T}<P_{T}\right) \leq \epsilon_{T},
$$

with $0 \leq \epsilon_{T} \leq 1$. In the following, we assume that the safety level is met exactly by the insurance companies, i.e., the condition expressed in Equation (14) becomes

$$
\operatorname{Pr}\left(A_{T}<P_{T}\right)=\epsilon_{T}
$$

Typically, the regulator defines the upper bound $\epsilon_{1}$ on the yearly ruin probability, $0 \leq \epsilon_{1} \leq 1$. Then, the probability of surviving $T$ periods is $(1-\epsilon)^{T}$. Hence, given $\epsilon_{1}$, we calculate the corresponding ruin probability for a $T$-year period $\epsilon_{T}$ as follows

$$
\epsilon_{T}=1-\left(1-\epsilon_{1}\right)^{T} .
$$

Model (B). Using an implementation that is closer to regulatory practice we consider that ruin can occur at any period $t^{*}, t^{*}=1, \ldots, T$ (cf. Section 2.2) and thus solvency is monitored on a yearly basis. The corresponding solvency requirement can be expressed through requiring

$$
R_{t}=\operatorname{Pr}\left(A_{t}<P_{t}\right) \leq \epsilon_{1}, \quad \forall t=1, \ldots, T
$$

where $\epsilon_{1}$ is the prescribed maximum one-year default probability introduced above. As in model (A), we suppose that insurance companies will fulfill this requirement exactly, i.e., we use the following conditions

$$
\operatorname{Pr}\left(A_{t}<P_{t}\right)=\epsilon_{1}, \quad \forall t=1, \ldots, T
$$

\subsection{Return and Utility Measurement}

We separately introduce the perspectives of the policyholders and equity holders on the contract assessment. For the policyholders, we consider their effective rate of return on investment and utility; for the equity holders, we introduce a return-on-equity measure. The values obtained from these measures allow us to discuss the optimal parameterization of the contract (e.g., with respect to the guarantee rate $g$ and the participation rate $\alpha$ ).

Return on Premiums ( $R o P)$. In a first step, we assume that the policyholders analyze the contract in light of the effective return they earn on their premiums invested in the product. In fact, to compare the insurance product with other investment opportunities, policyholders 
are interested in knowing to what the internal rate of return the final payoff corresponds. We call return on premiums ( $R o P)$ this measure that builds on the expected value of their payoff $\left(\mathbb{E}^{\mathbb{P}}\left[L_{T}\right]\right)$ under the real-world measure $\mathbb{P}$. Thus, RoP is defined as a solution of the equation

$$
\mathbb{E}^{\mathbb{P}}\left(L_{T}\right)=\sum_{t=0}^{T-1} \Pi_{t}(1+R o P)^{T-t} .
$$

Utility Function and Certainty Equivalent $(C E)$. Furthermore, following Schmeiser and Wagner (2015), we also let policyholders assess the contract through their individual preferences and the corresponding expected utility or certainty equivalent. We assume that the policyholder endowed with a level of wealth $w$ has a power (isoelastic) utility function given by

$$
U(w)=\frac{w^{1-\rho}}{1-\rho}
$$

where $\rho>0, \rho \neq 1$, is the Arrow-Pratt coefficient of relative risk aversion. Higher values of $\rho$ correspond to higher levels of risk aversion. The contract assessment is based on the expected utility of the final policyholder payoff $L_{T}$. Thus, we calculate the certainty equivalent $C E$ from

$$
U(C E)=\mathbb{E}^{\mathbb{P}}\left[U\left(L_{T}\right)\right]
$$

Return on Equity $(R o E)$. Finally, we assume equity holders to consider the yearly return on their investment when making decisions. We introduce the expected return on equity denoted by $R o E$ and defined as follows:

$$
R o E=\left(\frac{\mathbb{E}^{\mathbb{P}}\left[E_{T}\right]}{E_{0}}\right)^{1 / T}-1=\left(\frac{\mathbb{E}^{\mathbb{P}}\left[A_{T}-L_{T}\right]}{E_{0}}\right)^{1 / T}-1 .
$$

\subsection{Summary of the Model Framework}

In Figure 2, we summarize the model framework and present the outline for our analyses. From the parameters introduced, we focus on two contract parameters, the guaranteed interest rate $g$ and the surplus participation rate $\alpha$, and two environmental variables, the imposed solvency restriction on the annual ruin probability $\epsilon_{1}$ and the market risk-free return rate $r_{\mathrm{f}}$. Given a reference parameterization, we derive the (unique) position that the insurance company will take in terms of equity capital $E_{0}^{*}$ and asset allocation $\gamma_{t}^{*}$. The insurer's capital endowment and investment strategy will lead to a payoff distribution for the policyholder and the equity holder. The results are assessed using the return and expected utility concepts of $R o P$ and $C E$ and $R o E$, respectively. In our sensitivity analyses, we vary the values of the contract parameters and the environment variables to study the effects on the insurer's position and the consequences for the policyholder's and equity holder's valuation.

\section{Model Parameterization and Implementation}

In this section, we define the model parameters and the setup used as reference situation. First, we define the contract parameters, followed by the market with investment opportunities and solvency requirements. Table 1 summarizes the parameter settings, and Table 2 gives an overview of the further variables used. Detailed implementation notes are available in the Appendix. 


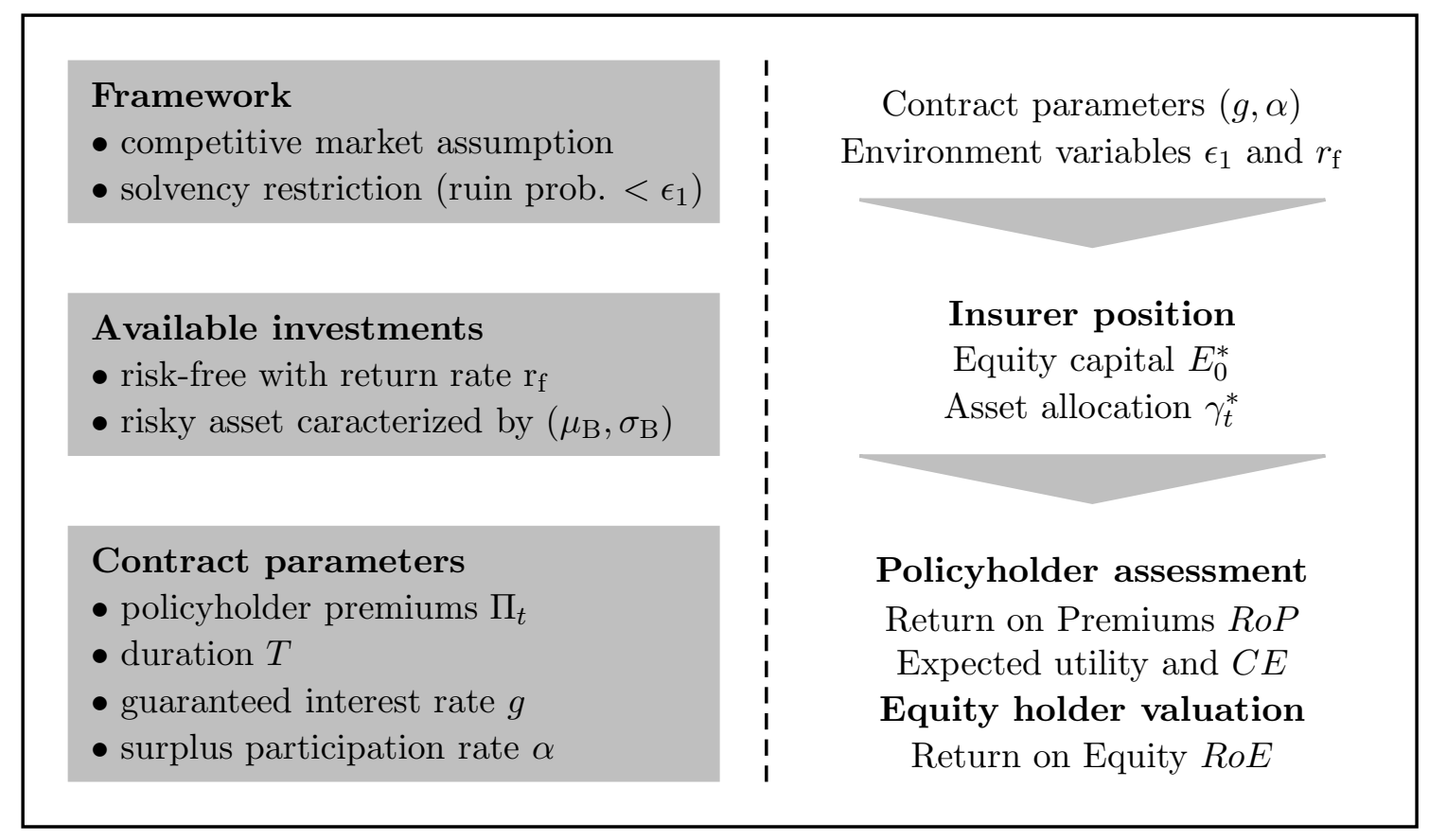

Figure 2: Overview of model framework assumptions and outline of analyses.

Contract parameters. Following Schmeiser and Wagner (2015), in model (A), the policyholder pays a single upfront unit premium $\Pi_{0}=1$ currency unit (C.U.) at the contract inception (all other $\Pi_{t}, t=1, \ldots, T-1$ are equal to zero). In model (B), periodic premiums $\Pi_{t}=1$ C.U. are paid at times $t=0, \ldots, T-1$, i.e., at the beginning of each year. In both models, we consider a contract with a duration of $T=10$ years. Using discounting by the risk-free interest rate $r_{\mathrm{f}}=1.5 \%$ (see below), the stream of payments in model (B) has a present value (at contract inception $t=0$ ) of 9.36 C.U.

As laid out in the Introduction, the maximum value of the annual interest rate guarantee is generally bounded from above by the regulators. For our reference setting, we consider that the insurance contract offered bears a value of $g=1 \%$ (between the maximum in force in Germany of 1.25 percent and in Switzerland of 0.75 percent). Furthermore, often a minimum participation rate for the policyholder is requested. We set the offered rate $\alpha=90 \%$ (in line with the minimum applied for certain type of contracts in Germany and in Switzerland). While these are the values set for the contract in the reference case, the values will be adapted in the course of our sensitivity analyses. For the policyholder risk aversion, we retain a single value $\rho=5$ for our reference case. This value is in line with the values used by other authors (cf. Schmeiser and Wagner, 2015; Braun et al., 2015; Schmeiser and Wagner, 2016).

Market and regulatory conditions. For the value of the risk-free interest rate, we consider the current market remuneration for very safe government bonds. Because the regulator considers the return of 10-year government bonds as a basis for calculating the upper bound for the interest rate guarantees, we take about the 2015-value of the 10-year rolling average of Swiss Government Bond yields and set $r_{\mathrm{f}}=1.5 \%$ (see also Figure 1). For the risky investment, we consider a portfolio composed to equal parts of the Swiss Market Index (SMI Index), the Euro Stoxx 50 Index (SX5E Index) and the S\&P 500 Index (SPX Index). We derive their annualized risk and return figures from a 20-year history of monthly data (January 1996 to December 2015). Given the historical returns, we calculate the central moments of the yearly return distribution 
by taking the correlation structure (annualized variance-covariance matrix) among the three indexes into account. From the above, we derive the drift and volatility parameters for the geometric Brownian motion process in our model and set $\left(\mu_{\mathrm{B}}, \sigma_{\mathrm{B}}\right)=(6.1 \%, 15.6 \%)$. Finally, we consider the solvency regulation in place in Switzerland (SST) and in the E.U. (Solvency II). As a surrogate to their full framework, we retain that the aim is to limit the frequency of defaults to a 1-in-200-year event. That is, we consider the yearly ruin probability and set its upper bound to $\epsilon_{1}=0.5 \%$. While this value applies directly under model (B), the ruin probability level allowed at maturity in model (A) will be equal to $\epsilon_{T}=1-\left(1-\epsilon_{1}\right)^{T}$ (cf. Equation 16). In the case of a $T=10$-year contract, we have $\epsilon_{T}=4.89 \% .^{5}$

\begin{tabular}{lll}
\hline Parameter & Variable & Value \\
\hline Policyholder premiums and risk aversion & & \\
Model (A), single upfront & $\Pi_{t}$ & $1.0 \cdot \mathbb{1}_{t=0}$ (C.U.) \\
Model (B), periodic & $\Pi_{t}$ & 1.0 (C.U.) \\
Arrow-Pratt coefficient of relative risk aversion & $\rho$ & 5 \\
\hline Contract & & \\
Duration & $T$ & 10 (years) \\
Guaranteed interest rate & $g$ & $1 \%$ \\
Annual surplus participation rate & $\alpha$ & $90 \%$ \\
\hline Capital market conditions & & \\
Risk-free rate of return & $r_{\mathrm{f}}$ & $1.5 \%$ \\
Drift of the geometric Brownian motion process & $\mu_{\mathrm{B}}$ & $6.1 \%$ \\
Volatility of the geometric Brownian motion process & $\sigma_{\mathrm{B}}$ & $15.6 \%$ \\
\hline Solvency regulation & & \\
$\quad$ One-year ruin probability (upper bound) & $\epsilon_{1}$ & $0.5 \%$ \\
\hline
\end{tabular}

Table 1: Parameterization of the reference case.

Notes: The time index $t$ in $\Pi_{t}$ runs from 0 to $T-1, \mathbb{1}_{t=0}$ denotes the indicator function with value equal to 1 if $t=0$ and 0 when $t \neq 0$, C.U. stands for currency unit.

\begin{tabular}{ll}
\hline Parameter & Variable \\
\hline Equity capital at contract inception & $E_{0}$ \\
Asset allocation (share invested risk-free) at times $t=0,1, \ldots, T-1$ & $\gamma, \gamma_{t}$ \\
Value of the insurer's assets at times $t=0,1, \ldots, T$ & $A_{t}$ \\
Value of the policyholder account at times $t=0,1, \ldots, T$ & $P_{t}$ \\
Insurer's portfolio investment return at times $t=1, \ldots, T$ & $R_{t}$ \\
Cost of the insurer's insolvency at times $t^{*}=1, \ldots, T$ & $D_{t^{*}}$ \\
Policyholder payoff at maturity $T$ & $L_{T}$ \\
Equity holder stake at time $T$ & $E_{T}$ \\
Policyholder return on premium & $R o P$ \\
Policyholder individual utility at maturity $T$ & $U\left(L_{T}\right)$ \\
Policyholder certainty equivalent from $\mathbb{E}\left[U\left(L_{T}\right)\right]$ & $C E$ \\
Equity holder return on equity & $R o E$ \\
\hline
\end{tabular}

Table 2: Summary of the variables used in the model.

\footnotetext{
${ }^{5}$ With this consideration, we importantly differentiate our reference setting from Schmeiser and Wagner (2015), where a ruin probability of $0.5 \%$ is considered for the 10 -year contract case.
} 


\section{Results and Analyses}

\subsection{Case of Model (A)}

Illustration of the reference situation. To illustrate the starting point for our analysis, we calculate the insurer's position in the parameterization of the reference case. We consider the market assumptions, an exact fulfillment of the solvency restriction and the insurance contract parameters as defined in Table 1 . We find a single solution $\left(E_{0}^{*}, \gamma^{*}\right)$, i.e., the insurer's equity capital and asset allocation, making the contract fair for both stakeholders (zero net present value, $N P V=0$, cf. Equations 12 and 13) and meeting the solvency requirement (Equation 15, $\left.R_{T}=\epsilon_{T}\right)$. We illustrate the solution in Figure 3, where we plot both conditions and their intersection point as the solution for the insurer's position (compare with Schmeiser and Wagner, 2015, Figure 2). We find $E_{0}^{*}=0.014$ and $\gamma^{*}=0.943$. The position $\left(E_{0}^{*}, \gamma^{*}\right)$ is completely set by the two conditions. In fact, on one hand, investing a higher amount of capital $E_{0}^{*}$ or more safely (higher value for $\gamma^{*}$ ) would make the contract unfair for equity holders. On the other hand, lower equity $E_{0}^{*}$ or a more risky investment (lower $\gamma^{*}$ ) would make the safety level unacceptable.

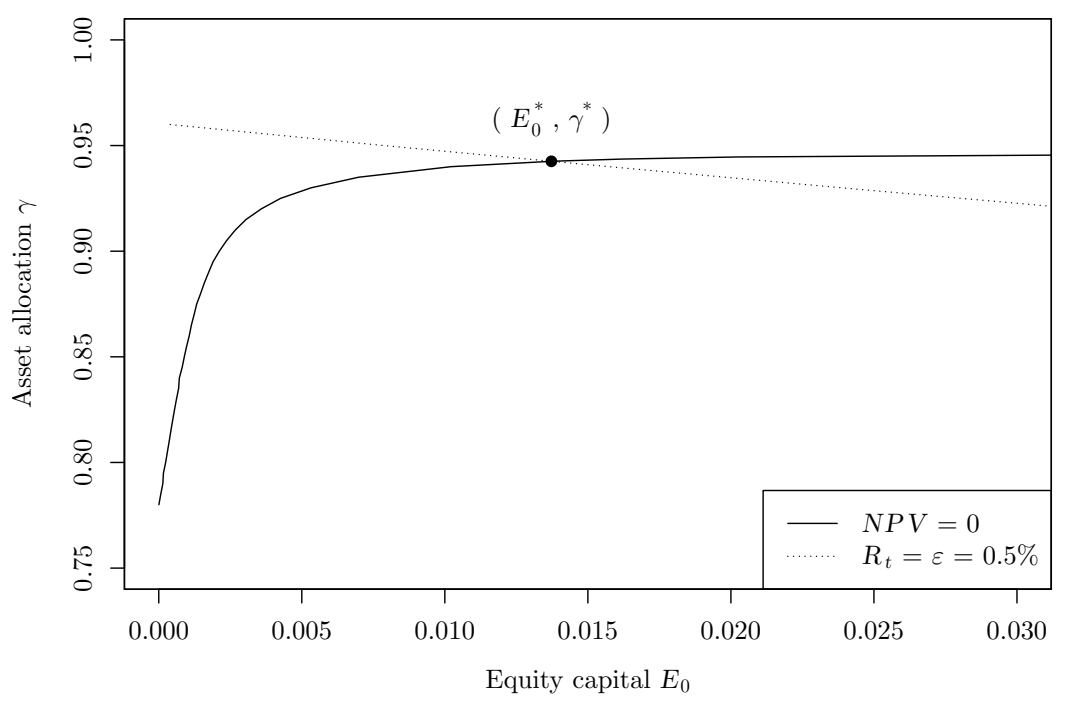

Figure 3: Illustration of the net present value $N P V$ and solvency constraints $R_{t}=\epsilon=0.5 \%$ defining the unique position of insurer equity capital $E_{0}^{*}$ and asset allocation $\gamma^{*}$ in model (A) under the reference case parameterization (see Table 1).

Below, we build on the reference case and analyze the sensitivity of the insurer's position and the impact on the policyholder assessment and equity holder valuation.

Impact of changes in the risk-free interest rate. As a first example (cf. Schmeiser and Wagner, 2015), we illustrate the impact of a decreasing risk-free interest rate $r_{\mathrm{f}}$ on the asset allocation and equity capital position, with all other parameters remaining unchanged. To some extent, this analysis reconsiders the evolution from the last years observed in the capital markets with an important decrease in the government bond yields (see Figure 1). We illustrate the insurer's position in terms of the equity capital and asset allocation in Figure 4(a) for values of the risk-free interest rate, which vary from $2.0 \%$ to $1.0 \%$. When the risk-free interest decreases, a larger share of the assets is invested in the risk-free asset and the capital 
invested by the equity holders decreases. In fact, the insurance positioning changes to comply with the solvency requirement (set ruin probability) and the fairness condition (zero net present value). The change in the insurer's position has a direct impact on the expected policyholder and equity holder returns. In fact, see Figure 4(b): within the scenario of a decreasing riskfree interest rate, the return on premium $R o P$ decreases down to the guaranteed interest rate $g$. The effective return of the contract is quickly limited to $g$, and the participation option in the insurer's profits becomes worthless, with $r_{\mathrm{f}} \rightarrow \log (1+g){ }^{6}$ Under this scenario, the return on equity $R o E$ changes little as long as $r_{\mathrm{f}}$ is away from $g$. When $r_{\mathrm{f}}$ approaches $g$, we have seen (Figure $4 \mathrm{a})$ that $E_{0}^{*}$ goes to zero. The $R o E$ towards the singular point $\left(E_{0}^{*}=0\right.$, no financing of the industry) tends to infinity. In Table 3 , we report the numerical values reported in Figure 4. Along with the insurer's position and the policyholder and equity holder returns, we add information on the expected policyholder payoff $\mathbb{E}\left(L_{T}\right)$, the standard deviation $\sigma\left(L_{T}\right)$ of the payoff and the corresponding certainty equivalent $C E$. We observe that with decreasing values of $r_{\mathrm{f}}$, the mean payoff decreases, as does the $R o P$ (see above). At the same time, as a consequence of the less risky asset allocation, the standard deviation decreases. The policyholders' $C E$ also decreases: the decreasing payoff values dominate the lower values of the volatility.

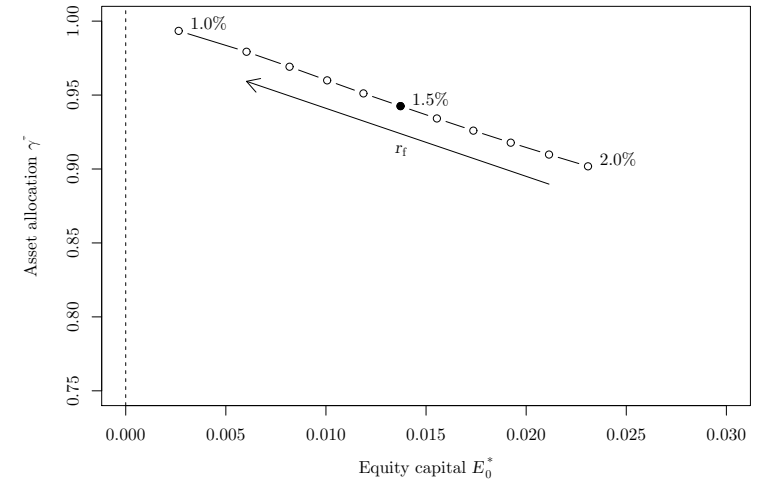

(a) Asset allocation $\gamma^{*}$ vs. equity capital $E_{0}^{*}$.

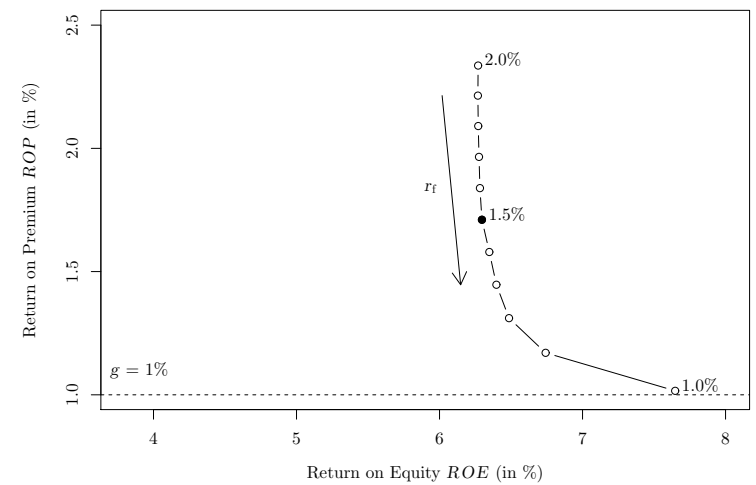

(b) Return on premium RoP vs. return on equity $R o E$.

Figure 4: Model (A) - Variation of the risk-free interest rate. Illustration of the asset allocation and equity capital insurer positions $\left(E_{0}^{*}, \gamma^{*}\right)$ and the resulting returns on premium and equity combinations $(R o E, R o P)$ under variation of the risk-free interest rate $r_{\mathrm{f}}$ between $2.0 \%$ and $1.0 \%$ (steps of $0.1 \%$ ). All other parameter values are taken from the reference case (see Table 1). Numerical values are reported in Table 3.

Impact of changes in the guaranteed interest rate. The guaranteed interest rate $g$ must comply with the product regulations. Often, a maximum value is set, but insurance companies are free to offer lower rates. In contrast to the analysis above, we now keep the risk-free interest rate $r_{\mathrm{f}}$ fixed, and we vary the value of the guaranteed interest rate $g$. In our model, setup $g$ is bound from above by $e^{r f}-1$ : that is, for higher values of $g$, no fair solution is possible. We study the result of decreasing this guaranteed interest $g$ on both equity holder and policyholder stakes. Our results are illustrated in Figure 5, and numerical values are reported

\footnotetext{
${ }^{6}$ Given that we used continuous compounding for $r_{\mathrm{f}}$ and discrete compounding for $g$ (see Equations 3 and 5 ), $r_{\mathrm{f}}=1.0 \%$ does not correspond to the limit point for $g=1.0 \%$. In fact, $r_{\mathrm{f}}$ could decrease to $\log (1+g) \approx 0.995 \%$.
} 


\begin{tabular}{|c|c|c|c|c|c|c|c|c|c|c|c|}
\hline \multicolumn{4}{|c|}{ Parameters (in \%) } & \multicolumn{2}{|c|}{ Insurer } & \multicolumn{4}{|c|}{ Policyholder } & \multicolumn{2}{|c|}{ Equity holder } \\
\hline$r_{\mathrm{f}}$ & $g$ & $\alpha$ & $\epsilon$ & $E_{0}^{*}$ & $\gamma^{*}$ & $\mathbb{E}\left(L_{T}\right)$ & $\sigma\left(L_{T}\right)$ & $\operatorname{RoP}(\%)$ & $C E$ & $\mathbb{E}\left(E_{T}\right)$ & RoE (\%) \\
\hline 2.0 & 1.0 & 90 & 0.5 & 0.023 & 0.902 & 1.260 & 0.056 & 2.34 & 1.254 & 0.0424 & 6.27 \\
\hline 1.9 & 1.0 & 90 & 0.5 & 0.021 & 0.910 & 1.245 & 0.051 & 2.21 & 1.240 & 0.0388 & 6.27 \\
\hline 1.8 & 1.0 & 90 & 0.5 & 0.019 & 0.918 & 1.230 & 0.046 & 2.09 & 1.226 & 0.0353 & 6.27 \\
\hline 1.7 & 1.0 & 90 & 0.5 & 0.017 & 0.926 & 1.215 & 0.040 & 1.97 & 1.212 & 0.0319 & 6.28 \\
\hline 1.6 & 1.0 & 90 & 0.5 & 0.016 & 0.934 & 1.200 & 0.035 & 1.84 & 1.197 & 0.0286 & 6.28 \\
\hline 1.5 & 1.0 & 90 & 0.5 & 0.014 & 0.943 & 1.185 & 0.030 & 1.71 & 1.183 & 0.0253 & 6.30 \\
\hline 1.4 & 1.0 & 90 & 0.5 & 0.012 & 0.951 & 1.170 & 0.025 & 1.58 & 1.168 & 0.0220 & 6.35 \\
\hline 1.3 & 1.0 & 90 & 0.5 & 0.010 & 0.960 & 1.154 & 0.020 & 1.45 & 1.154 & 0.0187 & 6.40 \\
\hline 1.2 & 1.0 & 90 & 0.5 & 0.008 & 0.969 & 1.139 & 0.015 & 1.31 & 1.139 & 0.0153 & 6.49 \\
\hline 1.1 & 1.0 & 90 & 0.5 & 0.006 & 0.979 & 1.123 & 0.009 & 1.17 & 1.123 & 0.0116 & 6.74 \\
\hline 1.0 & 1.0 & 90 & 0.5 & 0.003 & 0.993 & 1.106 & 0.002 & 1.02 & 1.106 & 0.0055 & 7.65 \\
\hline
\end{tabular}

Table 3: Model (A) - Variation of the risk-free interest rate. Results from the sensitivity analysis, see the caption of Figure 4. (The reference case value of $r_{\mathrm{f}}=1.5 \%$ is highlighted in bold face.)

in Table 4. For lower $g$, the insurance liabilities decrease and assets can be invested more riskily, allowing for lower values of the asset allocation ratio $\gamma^{*}$ (Figure 5a). At the same time, more equity capital $E_{0}^{*}$ to comply with solvency regulation is required; this equity capital gives good returns (increasing $R o E$, see Figure 5b). Additionally, policyholders participate in higher returns (from the more risky asset investments), leading to a higher return on their contributed premiums $R o P$. For values of $g$ close to $r_{\mathrm{f}}$, we observe effects that can be compared to the impact when $r_{\mathrm{f}}$ tends to $g$ (see the discussion above and Figure 4). In Table 4, we find that the policyholder utility (or certainty equivalent $C E$ ) increases for lower values of $g$ (in our ceteris paribus analysis) ${ }^{7}$

\begin{tabular}{|c|c|c|c|c|c|c|c|c|c|c|c|}
\hline \multicolumn{4}{|c|}{ Parameters (in \%) } & \multicolumn{2}{|c|}{ Insurer } & \multicolumn{4}{|c|}{ Policyholder } & \multicolumn{2}{|c|}{ Equity holder } \\
\hline$r_{\mathrm{f}}$ & $g$ & $\alpha$ & $\epsilon$ & $E_{0}^{*}$ & $\gamma^{*}$ & $\mathbb{E}\left(L_{T}\right)$ & $\sigma\left(L_{T}\right)$ & $\operatorname{RoP}(\%)$ & $C E$ & $\mathbb{E}\left(E_{T}\right)$ & $\operatorname{RoE}(\%)$ \\
\hline 1.5 & 1.5 & 90 & 0.5 & 0.004 & 0.989 & 1.164 & 0.003 & 1.53 & 1.164 & 0.0091 & 7.34 \\
\hline 1.5 & 1.0 & 90 & 0.5 & 0.014 & 0.943 & 1.185 & 0.030 & 1.71 & 1.183 & 0.0253 & 6.30 \\
\hline 1.5 & 0.5 & 90 & 0.5 & 0.018 & 0.910 & 1.201 & 0.050 & 1.85 & 1.196 & 0.0334 & 6.27 \\
\hline 1.5 & 0.0 & 90 & 0.5 & 0.022 & 0.881 & 1.216 & 0.069 & 1.97 & 1.206 & 0.0402 & 6.37 \\
\hline 1.5 & -0.5 & 90 & 0.5 & 0.025 & 0.853 & 1.230 & 0.087 & 2.09 & 1.215 & 0.0462 & 6.51 \\
\hline 1.5 & -1.0 & 90 & 0.5 & 0.027 & 0.827 & 1.244 & 0.105 & 2.20 & 1.222 & 0.0519 & 6.65 \\
\hline 1.5 & -1.5 & 90 & 0.5 & 0.030 & 0.801 & 1.257 & 0.122 & 2.31 & 1.229 & 0.0574 & 6.81 \\
\hline
\end{tabular}

Table 4: Model (A) - Variation of the interest rate guarantee. Results from the sensitivity analysis, see the caption of Figure 5. (The reference case value of $g=1.0 \%$ is highlighted in bold face.)

\footnotetext{
${ }^{7}$ In their paper, Braun et al. (2015) analyze in detail the level of guaranteed interest rate to choose to optimize the policyholders' utility while keeping the insurance product more valuable than a simple direct investment. The comparison of the utility from insurance contracts and from other investment forms has also been the focus of Schmeiser and Wagner (2015) and Schmeiser and Wagner (2016). In this latter study, transaction costs are also taken into account.
} 


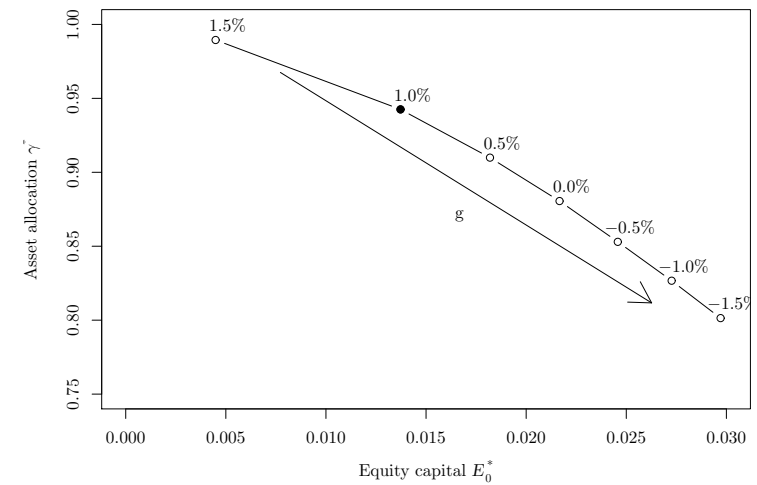

(a) Asset allocation $\gamma^{*}$ vs. equity capital $E_{0}^{*}$.

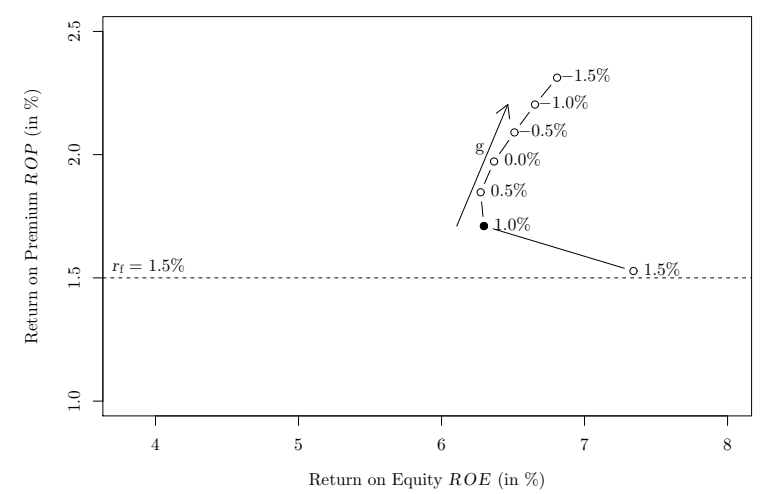

(b) Return on premium $R o P$ vs. return on equity $R o E$.

Figure 5: Model (A) - Variation of the interest rate guarantee. Illustration of the asset allocation and equity capital insurer positions $\left(E_{0}^{*}, \gamma^{*}\right)$ and the resulting returns on premium and equity combinations ( $R o E, R o P)$ under variation of the guaranteed interest rate $g$ between $1.5 \%$ and $-1.5 \%$ (steps of $0.5 \%$ ). All other parameter values are taken from the reference case (see Table 1). Numerical values are reported in Table 4.

Impact of changes in the surplus participation rate. In our model, the policyholder surplus participation $\alpha$ is a parameter fixed in advance by the insurer (following minimum participation rules set by the regulator). Increasing the value of $\alpha$ changes the insurer's position by increasing the value of the asset allocation ratio $\gamma^{*}$ and decreasing the equity capital. The results of the analyses are illustrated in Figure 5(a). The consequences of a higher value of $\alpha$ are very similar to the results obtained when the risk-free rate $r_{\mathrm{f}}$ decreases towards the guaranteed interest rate (compare with Figure 4a). Thus, given the changes in the insurer's asset allocation and equity capital, the $R_{o} P$ and $R_{o} E$ are modified (see Figure 5b). Despite increasing levels of participation, the resulting return on premiums decreases for policyholders. The equity holders' return decreases even more significantly. This result is particularly relevant for discussion on the adequate level of policyholder participation. Higher levels of participation diminish the attractiveness of the insurer's position and ultimately tend to make policyholders worse off than better off. This can also be observed as the policyholders' certainty equivalent $C E$ slightly decreases with increasing participation (see Table 5).

Impact of changes in the ruin probability. Finally, we also perform a sensitivity analysis on the ruin probability objective. A decrease of the ruin probability $\epsilon_{T}$ increases the solvency of the company. Not surprisingly, higher solvency levels come along with insurer positions at higher levels of equity capital $E_{0}^{*}$. The required asset allocation tends to be less risky, but the required change is less important (see Figure 7a). We also note that the equity holder's $R o E$ decreases a lot (more capital for similar asset allocation and returns), while the policyholder's $R o P$ decreases relatively little (see Figure 7b). Again, we also report the values in Table 6 . Here, we observe a slight decrease in policyholder utility (slight decrease in the $C E$ ).

\section{Impact of combined changes in the guaranteed interest and surplus participation} rates. From the previous sensitivity analyses, we observe two effects that would probably not have been the outcome of a "naive" contract assessment and that seem counter-intuitive at 


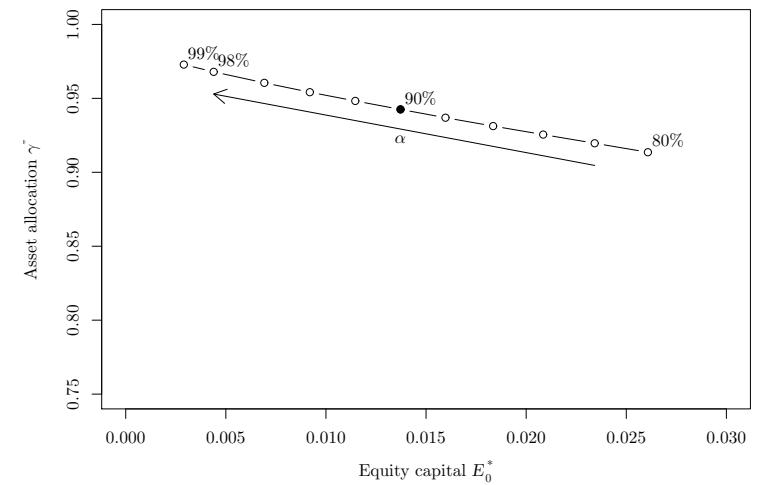

(a) Asset allocation $\gamma^{*}$ vs. equity capital $E_{0}^{*}$.

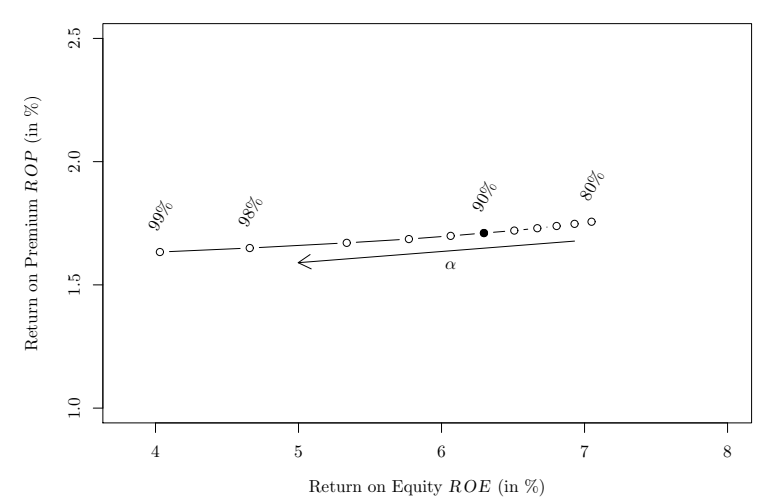

(b) Return on premium RoP vs. return on equity $R o E$.

Figure 6: Model (A) - Variation of the policyholder participation rate. Illustration of the asset allocation and equity capital insurer positions $\left(E_{0}^{*}, \gamma^{*}\right)$ and the resulting returns on premium and equity combinations ( $R o E, R o P)$ under variation of the policyholder participation rate $\alpha$ between $80 \%$ and $98 \%$ (steps of $2.0 \%$ ) and $99 \%$. All other parameter values are taken from the reference case (see Table 1).

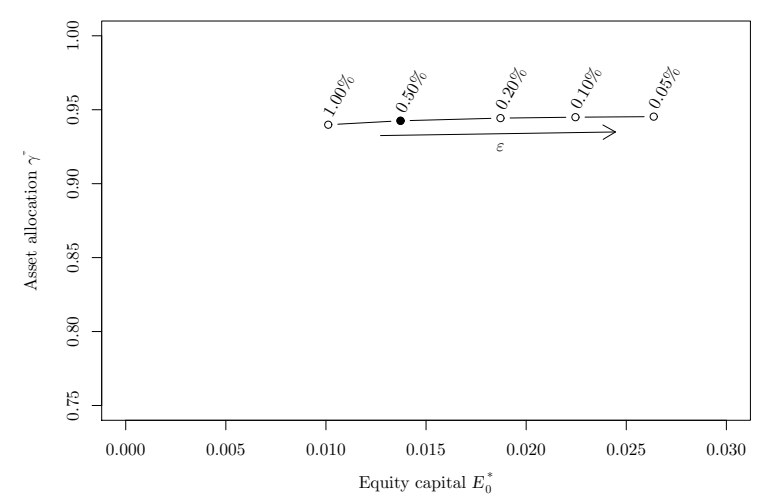

(a) Asset allocation $\gamma^{*}$ vs. equity capital $E_{0}^{*}$.

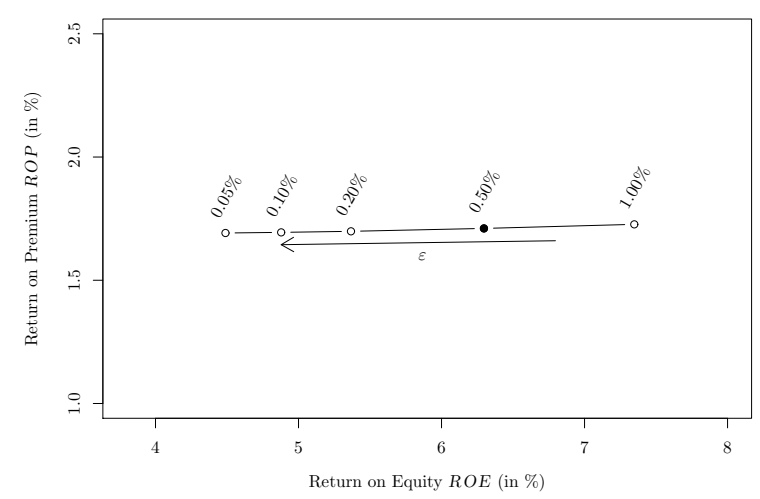

(b) Return on premium RoP vs. return on equity $R o E$.

Figure 7: Model (A) - Variation of the safety level. Illustration of the asset allocation and equity capital insurer positions $\left(E_{0}^{*}, \gamma^{*}\right)$ and the resulting returns on premium and equity combinations $(R o E, R o P)$ under variation of the ruin probability $\epsilon$ between $1.00 \%$ and $0.05 \%$. All other parameter values are taken from the reference case (see Table 1). Numerical values are reported in Table 6.

first sight. On one hand, the policyholder's $R o P$ and $C E$ increase with a ceteris paribus lower guaranteed interest rate or a lower surplus participation. On the other hand, these scenarios also increase the equity holder's $R o E$. We further underline this observation in the following.

In Figure 8(a)-(d), we illustrate the impact of contract changes in the guaranteed interest rate $g$ and policyholder participation $\alpha$ on the equity capital $E_{0}^{*}$, on the asset allocation $\gamma^{*}$, on the return on equity $R o E$ and on the return on premium $R o P$. Lowering the guaranteed interest rate $g$ and the policyholder surplus participation $\alpha$ impacts the capital amount to be invested $E_{0}^{*}$ and the allocation strategy $\gamma^{*}$ (see Figures $8 \mathrm{a}$ and b). Requiring a higher amount 


\begin{tabular}{|c|c|c|c|c|c|c|c|c|c|c|c|}
\hline \multicolumn{4}{|c|}{ Parameters (in \%) } & \multicolumn{2}{|c|}{ Insurer } & \multicolumn{4}{|c|}{ Policyholder } & \multicolumn{2}{|c|}{ Equity holder } \\
\hline$r_{\mathrm{f}}$ & $g$ & $\alpha$ & $\epsilon$ & $E_{0}^{*}$ & $\gamma^{*}$ & $\mathbb{E}\left(L_{T}\right)$ & $\sigma\left(L_{T}\right)$ & $\operatorname{RoP}(\%)$ & $C E$ & $\mathbb{E}\left(E_{T}\right)$ & RoE (\%) \\
\hline 1.5 & 1.0 & 80 & 0.5 & 0.026 & 0.914 & 1.190 & 0.038 & 1.76 & 1.187 & 0.0515 & 7.05 \\
\hline 1.5 & 1.0 & 82 & 0.5 & 0.023 & 0.920 & 1.189 & 0.036 & 1.75 & 1.186 & 0.0458 & 6.93 \\
\hline 1.5 & 1.0 & 84 & 0.5 & 0.021 & 0.926 & 1.188 & 0.035 & 1.74 & 1.186 & 0.0403 & 6.81 \\
\hline 1.5 & 1.0 & 86 & 0.5 & 0.018 & 0.931 & 1.187 & 0.033 & 1.73 & 1.185 & 0.0350 & 6.67 \\
\hline 1.5 & 1.0 & 88 & 0.5 & 0.016 & 0.937 & 1.186 & 0.032 & 1.72 & 1.184 & 0.0300 & 6.51 \\
\hline 1.5 & 1.0 & 90 & 0.5 & 0.014 & 0.943 & 1.185 & 0.030 & 1.71 & 1.183 & 0.0253 & 6.30 \\
\hline 1.5 & 1.0 & 92 & 0.5 & 0.011 & 0.948 & 1.183 & 0.028 & 1.70 & 1.182 & 0.0207 & 6.06 \\
\hline 1.5 & 1.0 & 94 & 0.5 & 0.009 & 0.954 & 1.182 & 0.026 & 1.69 & 1.181 & 0.0161 & 5.77 \\
\hline 1.5 & 1.0 & 96 & 0.5 & 0.007 & 0.960 & 1.180 & 0.023 & 1.67 & 1.179 & 0.0116 & 5.34 \\
\hline 1.5 & 1.0 & 98 & 0.5 & 0.004 & 0.968 & 1.178 & 0.020 & 1.65 & 1.177 & 0.0069 & 4.66 \\
\hline 1.5 & 1.0 & 99 & 0.5 & 0.003 & 0.973 & 1.176 & 0.017 & 1.63 & 1.175 & 0.0043 & 4.03 \\
\hline
\end{tabular}

Table 5: Model (A) - Variation of the policyholder participation rate. Results from the sensitivity analysis, see the caption of Figure 6. (The reference case value of $\alpha=90 \%$ is highlighted in bold face.)

\begin{tabular}{|c|c|c|c|c|c|c|c|c|c|c|c|}
\hline \multicolumn{4}{|c|}{ Parameters (in \%) } & \multicolumn{2}{|c|}{ Insurer } & \multicolumn{4}{|c|}{ Policyholder } & \multicolumn{2}{|c|}{ Equity holder } \\
\hline$r_{\mathrm{f}}$ & $g$ & $\alpha$ & $\epsilon$ & $E_{0}^{*}$ & $\gamma^{*}$ & $\mathbb{E}\left(L_{T}\right)$ & $\sigma\left(L_{T}\right)$ & $\operatorname{RoP}(\%)$ & $C E$ & $\mathbb{E}\left(E_{T}\right)$ & RoE (\%) \\
\hline 1.5 & 1.0 & 90 & 1.00 & 0.010 & 0.940 & 1.187 & 0.032 & 1.73 & 1.185 & 0.0206 & 7.35 \\
\hline 1.5 & 1.0 & 90 & 0.50 & 0.014 & 0.943 & 1.185 & 0.030 & 1.71 & 1.183 & 0.0253 & 6.30 \\
\hline 1.5 & 1.0 & 90 & 0.20 & 0.019 & 0.944 & 1.183 & 0.029 & 1.70 & 1.182 & 0.0316 & 5.37 \\
\hline 1.5 & 1.0 & 90 & 0.10 & 0.022 & 0.945 & 1.183 & 0.029 & 1.69 & 1.181 & 0.0362 & 4.88 \\
\hline 1.5 & 1.0 & 90 & 0.05 & 0.026 & 0.945 & 1.183 & 0.028 & 1.69 & 1.181 & 0.0409 & 4.49 \\
\hline
\end{tabular}

Table 6: Model (A) - Variation of the safety level. Results from the sensitivity analysis, see the caption of Figure 7. (The reference case value of $\epsilon=0.5 \%$ is highlighted in bold face.)

of equity makes the asset allocation chosen by the insurer more risky. At the same time, the expected $R o E$ increases (see Figure 8c). The increase of the $R o E$ stems mainly from the change in the policyholder's participation. Still, a decrease in the guaranteed interest rate $g$ and in the participation rate $\alpha$ is observed to be beneficial for the overall policyholder return RoP (see Figure 8d).

The underlying rationale for our results essentially stems from the lower promises made to the policyholder (guarantee and participation rates), allowing for a riskier asset allocation while simultaneously increasing the required capital (which is also better rewarded). As we have seen from the analyses above, these rewarding situations in terms of expected values typically bring higher uncertainty on the final payoff. This can be observed in the values for $\sigma\left(L_{T}\right)$ reported in Tables 4 and 3. However, the expected utility expressed through the certainty equivalent $C E$ can still increase (cf. our results reported using the risk aversion of $\rho=5$ ).

\subsection{Case of Model (B)}

Illustration of the evolution of the asset allocation. In model (B), while the level of equity capital $E_{0}$ will be fixed at contract inception for the whole duration (as seen in model A), the asset allocation is adapted by the insurer at the beginning of each period under consideration of the available assets. Available assets at time $t$ include the value at that time 


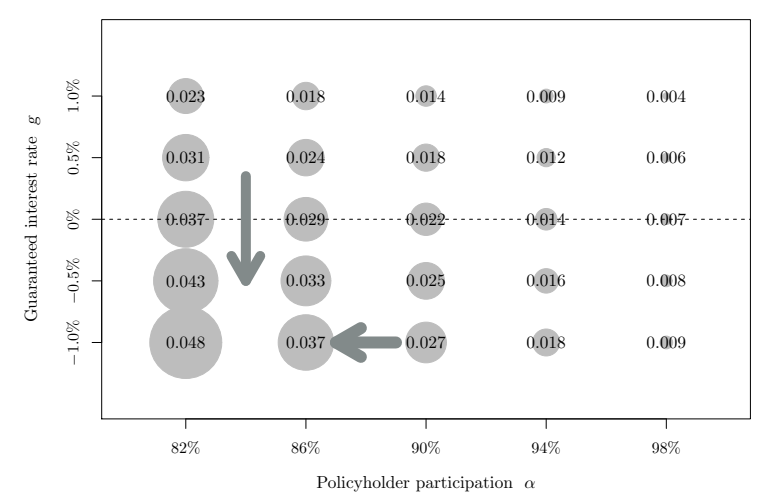

(a) Equity capital $E_{0}^{*}$

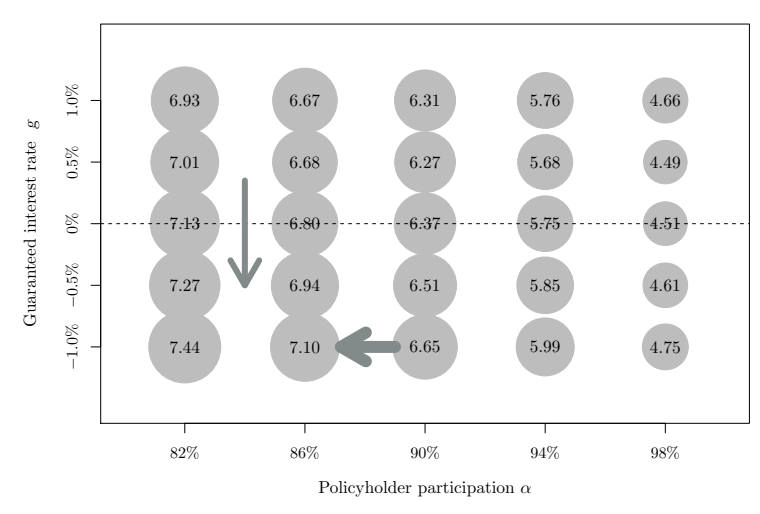

(c) Return on equity $\operatorname{RoE}$ (in \%)

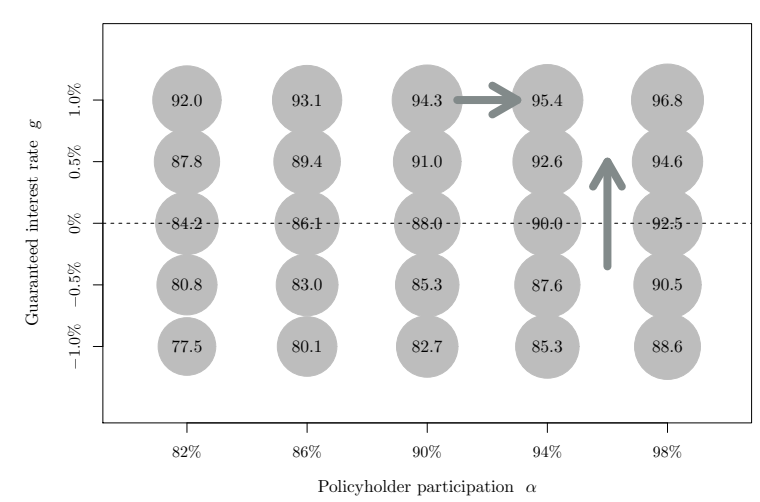

(b) Asset Allocation $\gamma^{*}$ (in \%)

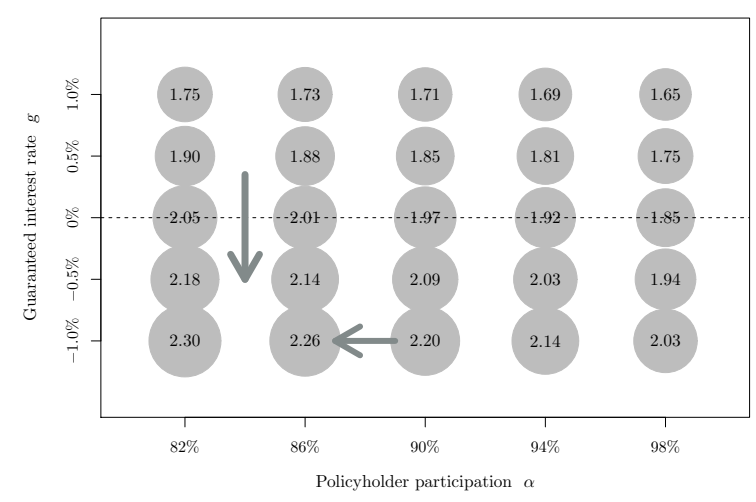

(d) Return on premium $\operatorname{RoP}($ in $\%$ )

Figure 8: Model A. Impact of contract changes in the guaranteed interest rate $g$ and policyholder participation $\alpha$ on the equity capital $E_{0}^{*}$, on the asset allocation $\gamma^{*}$, on the return on equity $R o E$ and on the return on premium $R o P$.

of the equity capital and premium income. Using the parameterization of the reference case reported in Table 1 , we find that the insurer will position at $E_{0}^{*}=0.053$. The yearly mean values of $\hat{\gamma}_{t}$ are reported in Table 7 and illustrated in Figure 9. We note that the asset allocation is more risky at the beginning of the contract $\left(\hat{\gamma}_{0}=0.822\right)$ than towards the end of the contract $\left(\hat{\gamma}_{T-1}=\hat{\gamma}_{9}=0.955\right)$. This dynamic stems from the fact that, at contract inception, a relatively high amount of equity capital $E_{0}^{*}$ compared to the contract premiums is available. In fact, in both models (A) and (B), we consider that equity holders invest a single upfront amount $E_{0}^{*}$ for the whole contract duration $T$. In model (B), considering the first year's premium amount, the initial equity capital $E_{0}$ is too large in comparison. This allows the insurer to invest more riskily under the solvency requirements (see Figure 9). We will see that this opportunity implies better expected returns on assets, i.e., higher expected returns on premiums and on equity (Figure 10). The (non-weighted) average value over the whole duration yields $\bar{\gamma}=\frac{1}{T} \sum_{t=0}^{T-1} \hat{\gamma}_{t}=0.932$.

The values of $E_{0}^{*}$ and $\bar{\gamma}$ can also be compared to the values obtained in model (A). Because the present value of premium payments is higher in model (B), 9.36 C.U. in model (B) against 1 C.U. in model (A), we expect a higher value of $E_{0}^{*}$ : see Section 3. Under the reference case parameterization, we have found $E_{0}^{*}=0.014$ in model $(\mathrm{A})$. The value of $E_{0}^{*}=0.053$ 


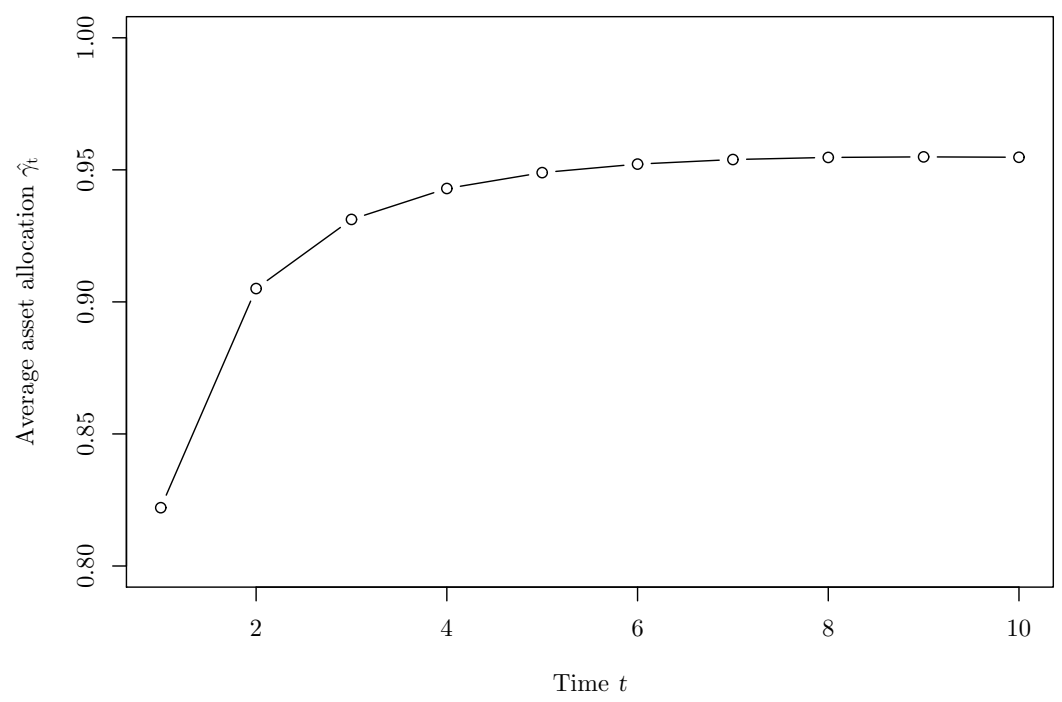

Figure 9: Illustration of the yearly (average) asset allocation $\hat{\gamma}_{t}$ under the model (B) reference case parameterization (see Table 1).

\begin{tabular}{ccccccccccc|c}
\hline$t$ & 0 & 1 & 2 & 3 & 4 & 5 & 6 & 7 & 8 & 9 & Mean \\
\hline$\hat{\gamma}_{t}$ & 0.822 & 0.905 & 0.931 & 0.943 & 0.949 & 0.952 & 0.954 & 0.955 & 0.955 & 0.955 & 0.932 \\
\hline
\end{tabular}

Table 7: Values of the yearly (average) asset allocation $\hat{\gamma}_{t}$ under the model (B) reference case parameterization (see Table 1).

is approximately four times higher, essentially due to the higher contract value in terms of premiums. The asset allocation for the whole duration in model (A) has yielded $\gamma^{*}=0.943$. This is relatively close to the average value $\bar{\gamma}=0.932$ found in model (B).

Sensitivity analyses. In the following, we present sensitivity analyses for parameter ranges similar to the ones used in Section 4.1. We present our results in the graphs in Figure 10. Numerical values are reported in the Tables 10 to 13 in the Appendix. In the graphs in Figure 10, the asset allocation and equity capital insurer positions $\left(E_{0}^{*}, \bar{\gamma}\right)$ and the resulting returns on premium and equity combinations $(R o E, R o P)$ are illustrated. Figures 10(a) and (b) present the results for variations of the risk-free interest rate $r_{\mathrm{f}}$. The graphs (c) and (d) report the results for different values of the guaranteed interest rate $g$. The sensitivity analysis on the policyholder participation rate $\alpha$ is presented in graphs (e) and (f), while the results for different values of the ruin probability $\epsilon$ are given in graphs (g) and (h).

We now compare the results from the sensitivity analyses reported in Figure 10 with the results obtained in the framework of model (A), i.e., Figures 4 to 7 of Section 4.1. While the numerical results are different (in terms of absolute numbers), the overall shape and behavior of the insurer position and the resulting returns remains very similar. In the case where the riskfree interest $r_{\mathrm{f}}$ diminishes, we observe in both models decreasing equity capital positions and a more conservative asset allocation that leads to lower policyholder returns. When decreasing the guaranteed interest $g$, we see the opposite trends with increasing equity, riskier asset allocation and higher returns on premiums. Additionally, in both models, an increase in the policyholder 
C. Mirza and J. Wagner - Participating Life Insurance: Which Contracts Are Win-Win?

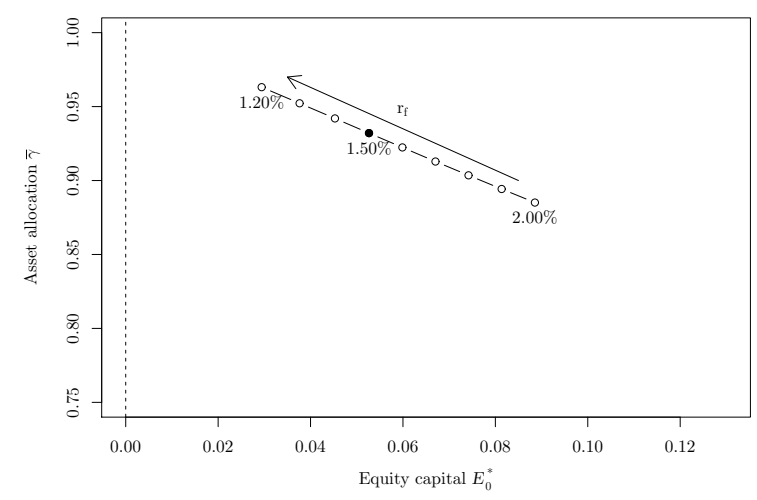

(a) Variation of the risk-free interest $r_{\mathrm{f}}$

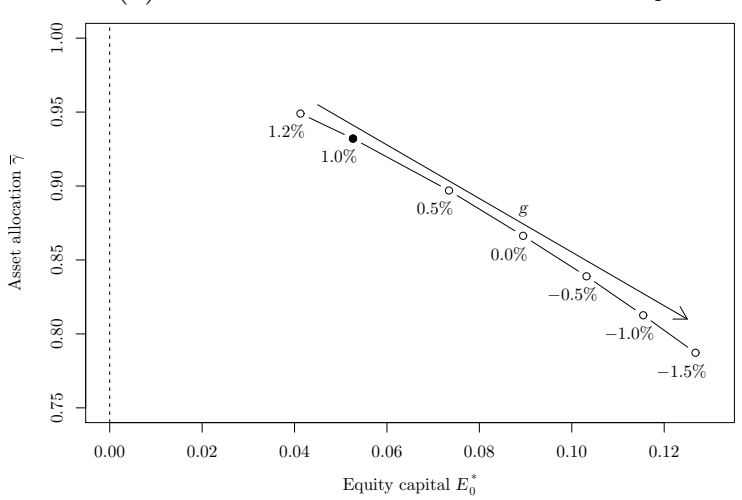

(c) Variation of the guaranteed interest $g$

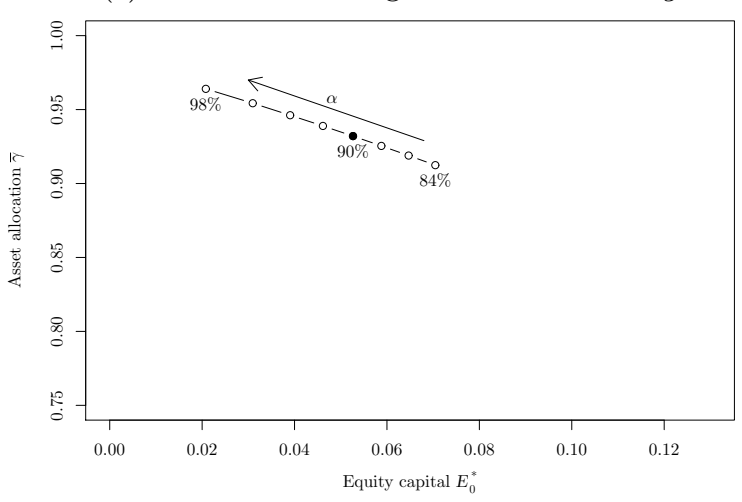

(e) Variation of the policyholder participation $\alpha$

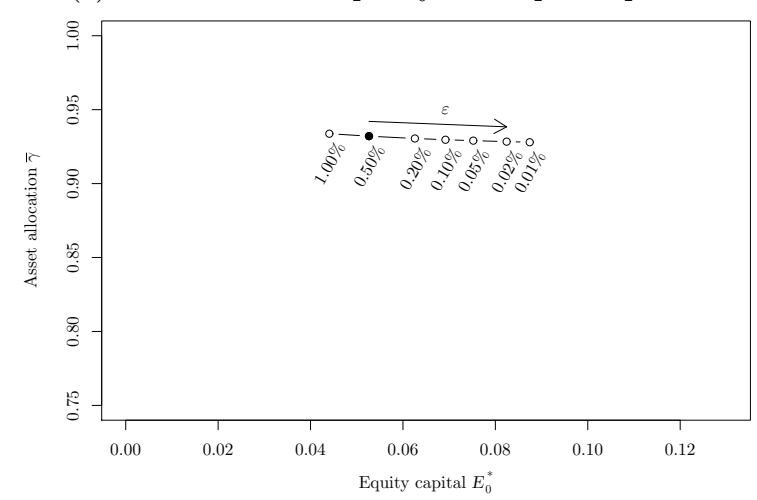

(g) Variation of the ruin probability $\epsilon$

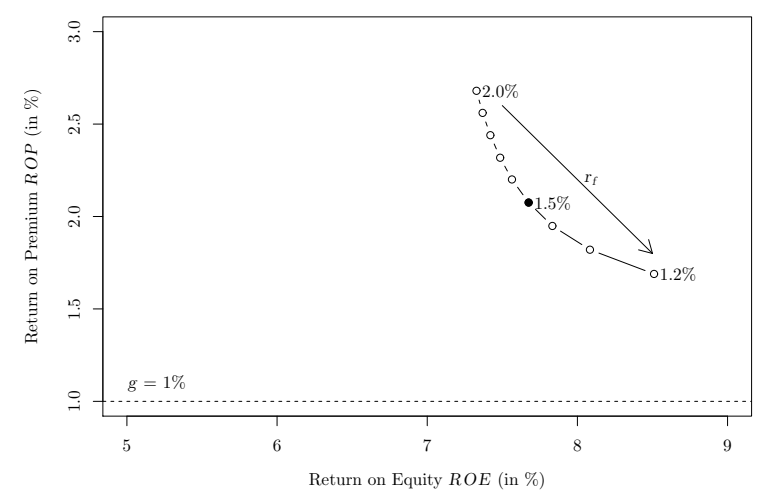

(b) Variation of the risk-free interest $r_{\mathrm{f}}$

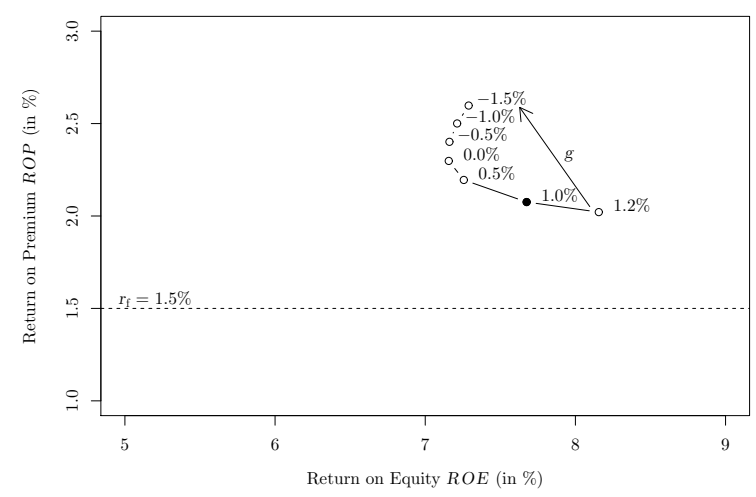

(d) Variation of the guaranteed interest $g$

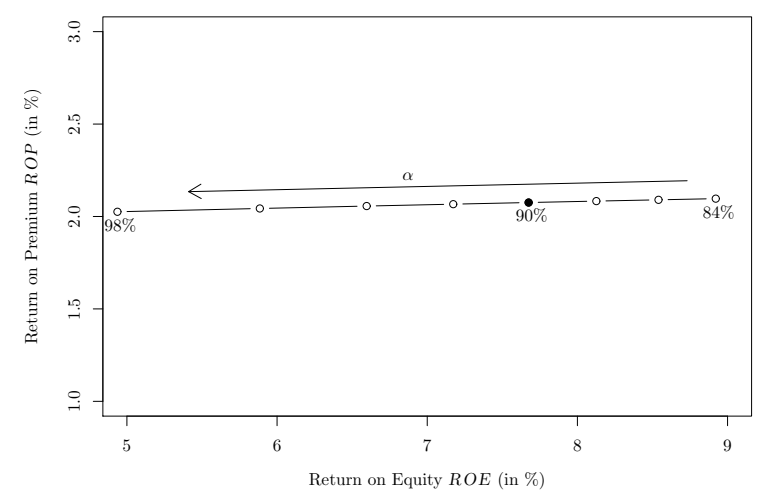

(f) Variation of the policyholder participation $\alpha$

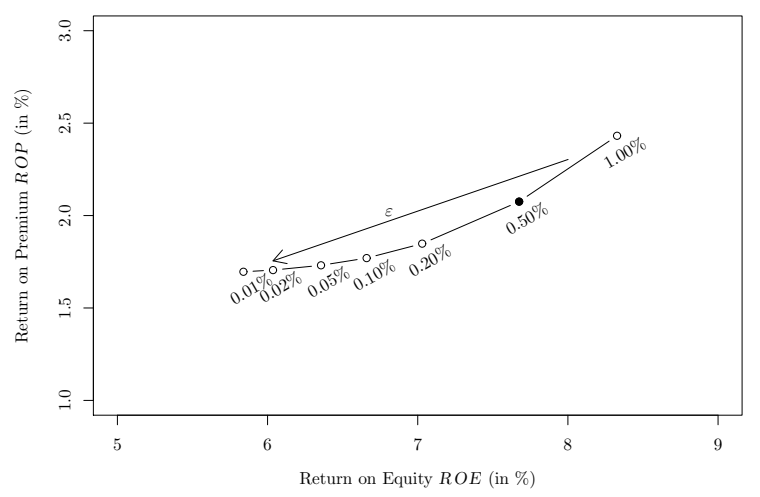

(h) Variation of the ruin probability $\epsilon$

Figure 10: Sensitivity analyses in Model $(B)$. Illustration of the positions $\left(E_{0}^{*}, \bar{\gamma}^{*}\right)$ and the returns combinations $(R o E, R o P)$ under variation of the risk-free interest $r_{\mathrm{f}}$, the guaranteed interest $g$, the policyholder participation $\alpha$ and the ruin probability $\epsilon$. Parameter values are taken from the reference case (see Table 1). 
participation rate $\alpha$ has similar effects on the insurer position than the decreasing risk-free rate scenario. In terms of returns, mainly the return on equity is decreasing. As observed before, a lower required ruin probability $\epsilon$ impacts the amount of capital needed and decreases the equity holder's return. In model (B), the return on premiums is also affected (more negatively than in model A).

\section{Conclusion}

We use a contingent claims model framework to assess the equity holder's and policyholder's stakes in life and pension insurance products. We assume contracts with interest rate guarantees and profit participation that are regulated by solvency requirements. We build our analysis on earlier studies, particularly the most recent work by Schmeiser and Wagner (2015). Given the difficult capital market environment and the solvency requirements, offering guarantees that are rewarding for equity holders and policyholders has become a challenge. We aim at determining the key parameter values that optimize the value proposition of such contracts.

Our study is based on a reference setup on which we apply parameter sensitivity analyses. For given contract parameters (duration, interest rate guarantee and surplus participation rate) under prevailing market conditions (risk-free rate of return, risky investment) and solvency regulation (maximum ruin probability) we numerically derive the capital needed and the asset allocation. Our main findings on the contract parameters are as follows:

- Decreasing the interest rate guarantee allows for a higher investment share in the risky asset while requiring higher equity capital; thereby policyholder and equity holder returns increase.

- Decreasing the participation rate has a similar impact on the investment and the capital; thereby essentially equity holder returns increase along with a lower increase of policyholder returns.

With regard to the market and regulatory conditions we find that a lower required ruin probability implies more equity capital and lower return on equity. A decreasing risk-free interest rate implies a higher share of riskless investments, lower equity capital and diminishing policyholder returns.

In summary, we find that contracts with lower guarantees and lower participation rates can still imply higher customer returns. The rationale behind this finding is that the assets linked to such contracts can be invested more riskily because solvency constraints for given capital are alleviated. The policyholder's assets are still protected against downsides by the minimum return guarantee. Furthermore, the return on equity for the investors increases, while higher capital amounts can be attracted and are needed.

In the first model considered (cf. also Schmeiser and Wagner, 2015), solvency is controlled for at maturity and a single premium is paid upfront. While this hypothesis can be justified as long as payouts only occur at maturity, the practice of solvency regulation requires yearly assessments that may imply adaptations in the asset allocation. Thus, our second model considers yearly solvency testing and allows for periodic premium payments. Putting side-by-side the models for one-year and at-maturity solvency requirements, as well as single and periodic premiums, we find that the conceptual results remain similar, i.e., the previously found win-win situations for both policyholders and equity holders still exist. However, the numerical values at which these situations occur may be significantly different. Therefore, we conclude that, despite necessary 
model assumptions and simplifications, modeling that is "close enough" to real life is essential, particularly when the market landscape is highly competitive.

\section{References}

Baloise Group, 2015, Baloise sells closed life insurance portfolio in Germany, Media Information.

Bernard, C., O. Le Courtois, and F. Quittard-Pinon, 2005, Market value of life insurance contracts under stochastic interest rates and default risk, Insurance: Mathematics and Economics, 36(3):499-516.

Braun, A., M. Fischer, and H. Schmeiser, 2015, How to Derive Optimal Guarantee Levels in Participating Life Insurance Contracts, I. VW-HSG Working Paper, University of St. Gallen.

Braun, A., H. Schmeiser, and F. Schreiber, 2018, Return on Risk-Adjusted Capital under Solvency II: Implications for the Asset Management of Insurance Companies, Geneva Papers on Risk and Insurance - Issues and Practice, (forthcoming).

Briys, E. and F. de Varenne, 1997, On the Risk of Insurance Liabilities: Debunking Some Common Pitfalls, The Journal of Risk and Insurance, 64(4):673-694.

Butsic, R. P., 1994, Solvency Measurement for Property-Liability Risk-Based Capital Applications, The Journal of Risk and Insurance, 61(4):656-690.

Doherty, N. and J. Garven, 1986, Price Regulation in Property-Liability Insurance: A Contingent-Claims Approach, Journal of Finance, 41(5):1031-1050.

Eling, M., N. Gatzert, and H. Schmeiser, 2008, The Swiss Solvency Test and its Market Implications, The Geneva Papers on Risk and Insurance - Issues and Practice, 33(3):418-439.

Eling, M. and S. Holder, 2013a, Maximum Technical Interest Rates in Life Insurance in Europe and the United States: An Overview and Comparison, The Geneva Papers on Risk and Insurance - Issues and Practice, 38(2):354-375.

Eling, M. and S. Holder, 2013b, The Value of Interest Rate Guarantees in Participating Life Insurance Contracts: Status Quo and Alternative Product Design, Insurance: Mathematics and Economics, 53(3):491-503.

European Commission, 2015, Commission Delegated Decision (EU) 2015/1602, Official Journal of the European Union, L248.

European Union, 1992, Council Directive 92/96/EEC of the European Parliament and of the Council, Official Journal of the European Communities, L360.

European Union, 2002, Directive 2002/83/EC of the European Parliament and of the Council, Official Journal of the European Communities, L345.

European Union, 2009, Directive 2009/138/EC of the European Parliament and of the Council, Official Journal of the European Union, L335.

European Union, 2014, Directive 2014/51/EU of the European Parliament and of the Council, Official Journal of the European Union, L153.

Federal Assembly of the Swiss Confederation, 2004, Insurance Supervision Act (961.01).

Gatzert, N., I. Holzmüller, and H. Schmeiser, 2012, Creating Customer Value in Participating Life Insurance, The Journal of Risk and Insurance, 79(3):645-670. 
Gatzert, N. and A. Kling, 2007, Analysis of Participating Life Insurance Contracts: A Unification Approach, The Journal of Risk and Insurance, 74(3):547-570.

German Federal Ministry of Justice, 2014a, Verordnung über die Mindestbeitragsrückerstattung in der Lebensversicherung (MindZV).

German Federal Ministry of Justice, 2014b, Verordnung über Rechnungsgrundlagen für die Deckungsrückstellungen (DeckRV).

Grosen, A. and P. Jorgensen, 2000, Fair Valuation of Life Insurance Liabilities: The Impact of Interest Rate Guarantees, Surrender Options, and Bonus Policies, Insurance: Mathematics and Economics, 26(1):37-57.

Grosen, A. and P. Jorgensen, 2002, Life Insurance Liabilities at Market Value: An Analysis of Insolvency Risk, Bonus Policy, and Regulatory Intervention Rules in a Barrier Option Framework, The Journal of Risk and Insurance, 69(1):63-91.

International Association of Insurance Supervisors, 2016, 2015 Global Insurance Market Report, Technical Report.

Killer, M., 2015, Streit um BVG-Gelder - Für eine höhere Mindestquote, Neue Zürcher Zeitung, 23 January.

Kling, A., A. Richter, and J. Ruß, 2007a, The Impact of Surplus Distribution on the Risk Exposure of With Profit Life Insurance Policies Including Interest Rate Guarantees, The Journal of Risk and Insurance, 74(3):571-589.

Kling, A., A. Richter, and J. Ruß, 2007b, The Interaction of Guarantees, Surplus Distribution, and Asset Allocation in With-Profit Life Insurance Policies, Insurance: Mathematics and Economics, 40(1):164-178.

Merton, R. C., 1969, Lifetime Portfolio Selection under Uncertainty: The Continuous-Time Case, The Review of Economics and Statistics, 51(3):247-257.

Rymaszewski, P., H. Schmeiser, and J. Wagner, 2012, Under What Conditions Is an Insurance Guaranty Fund Beneficial for Policyholders?, The Journal of Risk and Insurance, 79(3):785815.

Schmeiser, H. and J. Wagner, 2013, The Impact of Introducing Insurance Guaranty Schemes on Pricing and Capital Structure, The Journal of Risk and Insurance, 80(2):273-308.

Schmeiser, H. and J. Wagner, 2015, A Proposal on How the Regulator Should Set Minimum Interest Rate Guarantees in Participating Life Insurance Contracts, The Journal of Risk and Insurance, 82(3):659-686.

Schmeiser, H. and J. Wagner, 2016, What Transaction Costs are Acceptable in Life Insurance Products from the Policyholders' Viewpoint?, Journal of Risk Finance, 17(3):277-294.

Swiss Federal Council, 2005, Ordinance on the Supervision of Private Insurance Companies (961.011). 


\section{Appendix}

\section{Model implementation}

Implementation notes for the model (A). Because no closed-form solutions are available for the policyholder payoff $L_{T}$ (Equation 7 ) and the equity holder stake $E_{T}$ (Equation 8), we use the Monte Carlo simulation technique. In both models (A) and (B), we generate $N=100000$ different realizations over the period of $T$ years. The iterative calculations at times $t$ of $A_{t}$ and $P_{t}$ are straightforward. The main challenge is the calculation of the required equity capital $E_{0}^{*}$ and the asset allocation $\gamma^{*}$. For deriving both quantities, we make use of the competitive market constraint (Equation 13) and the solvency requirement (Equation 15). The implementation of the algorithm follows the following steps:

1. Generate $N \times T$ independent identically distributed (iid) random variables (rv) from a standard normal distribution $W_{t}^{i} \sim N(0,1)$, where $i=1,2, \ldots, N$, and $t=1,2, \ldots, T$.

2. For an initial asset allocation $\gamma \in(0,1)$, calculate $A_{t}^{i, \mathbb{P}}(\gamma)$ and $P_{t}^{i, \mathbb{P}}(\gamma)$ (cf. Equations 3 and 5 , respectively) and $A_{t}^{i, \mathbb{Q}}(\gamma)$ and $P_{t}^{i, \mathbb{Q}}(\gamma)$ at each time $t$ and for each scenario $i$ under the $\mathbb{P}$ - and $\mathbb{Q}$-measures, respectively. ${ }^{8}$

3. Define the capital needed $E_{0}^{i}(\gamma)$ such that $A_{T}^{i, \mathbb{P}}(\gamma)-P_{T}^{i, \mathbb{P}}(\gamma)=0$ in each scenario $i$. Order the obtained $E_{0}^{i}(\gamma)$ such that, $E_{0}^{i: N}(\gamma) \geq E_{0}^{(i+1): N}(\gamma)$ for any $i \in\{1,2, \cdots, N\}$. Given the upper bound for the probability of ruin $\epsilon_{T}$ define the function $E_{0}(\gamma)$ such that $E_{0}(\gamma)=$ $E_{0}^{\left\lceil\epsilon_{T} \cdot N\right\rceil: N}(\gamma)$.

4. Using $E_{0}(\gamma)$ for the initial equity capital in $A_{t}^{i, \mathbb{Q}}(\gamma)$, introduce the Monte Carlo approximation of the policyholder contract's net present value under the $\mathbb{Q}$-measure

$$
\widehat{N P V}(\gamma)=\frac{1}{N} \sum_{i=1}^{N}\left[P_{T}^{i, \mathbb{Q}}(\gamma)-\max \left(P_{T}^{i, \mathbb{Q}}(\gamma)-A_{T}^{i, \mathbb{Q}}(\gamma), 0\right)\right] \cdot e^{-r_{\mathrm{f}} \cdot T}-P_{0}
$$

5. Numerically find $\gamma^{*} \in(0,1)$ as the solution of $\widehat{N P V}\left(\gamma^{*}\right)=0$ and set $E_{0}^{*}=E_{0}\left(\gamma^{*}\right)$ using the above. The optimal insurer position is given by the pair $\left(E_{0}^{*}, \gamma^{*}\right)$.

Implementation notes for the model (B). In the numerical implementation, we will make use of the solvency requirement (18) and competitive market-pricing constraint (12).

- First, we derive a formula to calculate the asset allocation $\gamma_{t}$ from (18), where $\gamma_{t}$ at time $t$ is a function of the assets $A_{t-1}$, the policyholder account $P_{t-1}$ and the premium $\Pi_{t-1}$ from the previous period $(t-1)$, as well as the given contract parameters $\left(g\right.$ and $\left.\epsilon_{1}\right)$ and the given available investments (parameters $r_{\mathrm{f}}, \mu_{B}$, and $\sigma_{\mathrm{B}}$ ).

\footnotetext{
${ }^{8}$ For the evaluation under the $\mathbb{Q}$-measure, $\mu_{\mathrm{B}}$ is replaced by $r_{\mathrm{f}}$ in Equation (4), defining $R_{t}^{\mathbb{Q}}$.
} 
Consider the event $\mathbb{A}_{t}=\left\{A_{t}-P_{t}<0\right\}$ :

$$
\begin{aligned}
\mathbb{A}_{t} & \Longleftrightarrow\left\{\left(A_{t-1}+\Pi_{t-1}\right) \cdot\left(1+R_{t}^{\mathbb{P}}\right)-\left(P_{t-1}+\Pi_{t-1}\right) \cdot\left(1+\max \left(g, \alpha R_{t}^{\mathbb{P}}\right)\right)<0\right\} \\
& \Longleftrightarrow\left\{\theta_{t-1} \cdot\left(1+R_{t}^{\mathbb{P}}\right)-\left(1+\max \left(g, \alpha R_{t}^{\mathbb{P}}\right)\right)<0\right\}, \text { with } \theta_{t-1}=\frac{A_{t-1}+\Pi_{t-1}}{P_{t-1}+\Pi_{t-1}}>1^{9} \\
& \Longleftrightarrow \begin{cases}\left\{\theta_{t-1} \cdot\left(1+R_{t}^{\mathbb{P}}\right)-\left(1+\alpha R_{t}^{\mathbb{P}}\right)<0\right\} & \text { if } g<\alpha R_{t}^{\mathbb{P}} \\
\left\{\theta_{t-1} \cdot\left(1+R_{t}^{\mathbb{P}}\right)-(1+g)<0\right\} & \text { otherwise }\end{cases} \\
& \Longleftrightarrow \begin{cases}\left\{R_{t}^{\mathbb{P}}<\frac{1-\theta_{t-1}}{\theta_{t-1}-\alpha}\right\} & \text { if } g / \alpha<R_{t}^{\mathbb{P}} \\
\left.R_{t}^{\mathbb{P}}<\frac{1+g}{\theta_{t-1}}-1\right\} & \text { otherwise }\end{cases}
\end{aligned}
$$

Thus, from Equation (18),

$$
\begin{aligned}
& \operatorname{Pr}\left(\mathbb{A}_{t}\right)=\epsilon_{t} \\
& \Longleftrightarrow \operatorname{Pr}\left(R_{t}^{\mathbb{P}}<\frac{1-\theta_{t-1}}{\theta_{t-1}-\alpha} \mid R_{t}^{\mathbb{P}}>\frac{g}{\alpha}\right) \cdot \operatorname{Pr}\left(R_{t}^{\mathbb{P}}>\frac{g}{\alpha}\right) \\
& +\operatorname{Pr}\left(R_{t}^{\mathbb{P}}<\frac{1+g}{\theta_{t-1}}-1 \mid R_{t}^{\mathbb{P}}<\frac{g}{\alpha}\right) \cdot \operatorname{Pr}\left(R_{t}^{\mathbb{P}}<\frac{g}{\alpha}\right)=\epsilon_{t} \\
& \Longleftrightarrow \operatorname{Pr}\left(\frac{g}{\alpha}<R_{t}^{\mathbb{P}}<\frac{1-\theta_{t-1}}{\theta_{t-1}-\alpha}\right)+\operatorname{Pr}\left[R_{t}^{\mathbb{P}}<\left(\frac{1+g}{\theta_{t-1}}-1\right) ; R_{t}^{\mathbb{P}}<\frac{g}{\alpha}\right]=\epsilon_{t} \\
& \Longleftrightarrow \begin{cases}\operatorname{Pr}\left(\frac{g}{\alpha}<R_{t}^{\mathbb{P}}<\frac{1-\theta_{t-1}}{\theta_{t-1}-\alpha}\right)+\operatorname{Pr}\left(R_{t}^{\mathbb{P}}<\frac{g}{\alpha}\right)=\epsilon_{t} & \text { if } \theta_{t-1}<\theta^{* 10} \\
\operatorname{Pr}\left(R_{t}^{\mathbb{P}}<\frac{1+g}{\theta_{t-1}}-1\right)=\epsilon_{t} & \text { otherwise }^{11}\end{cases} \\
& \Longleftrightarrow \begin{cases}\operatorname{Pr}\left(R_{t}^{\mathbb{P}}<\frac{1-\theta_{t-1}}{\theta_{t-1}-\alpha}\right)=\epsilon_{t} & \text { if } \theta_{t-1}<\theta^{*} \\
\operatorname{Pr}\left(R_{t}^{\mathbb{P}}<\frac{1+g}{\theta_{t-1}}-1\right)=\epsilon_{t} & \text { otherwise }\end{cases} \\
& \Longleftrightarrow \begin{cases}\operatorname{Pr}\left[W_{t}^{\mathbb{P}}-W_{t-1}^{\mathbb{P}}<\frac{1}{\sigma_{\mathrm{B}}} \ln \left(\frac{\frac{1-\alpha}{\theta_{t-1}-\alpha}-\gamma_{t} e^{r_{\mathrm{f}}}}{\left(1-\gamma_{t}\right) e^{\mu_{B}-\sigma_{\mathrm{B}}^{2} / 2}}\right)\right]=\epsilon_{t} & \text { if } \theta_{t-1}<\theta^{*} \\
\operatorname{Pr}\left[W_{t}^{\mathbb{P}}-W_{t-1}^{\mathbb{P}} \leq \frac{1}{\sigma_{\mathrm{B}}} \ln \left(\frac{\frac{1+g}{\theta_{t-1}}-\gamma_{t} e^{r_{\mathrm{f}}}}{\left(1-\gamma_{t}\right) e^{\mu_{B}-\sigma_{\mathrm{B}}^{2} / 2}}\right)\right]=\epsilon_{t} & \text { otherwise }\end{cases} \\
& \Longleftrightarrow\left\{\begin{array}{l}
\frac{1}{\sigma_{\mathrm{B}}} \ln \left(\frac{\frac{1-\alpha}{\theta_{t-1}-\alpha}-\gamma_{t} e^{r_{\mathrm{f}}}}{\left(1-\gamma_{t}\right) e^{\mu_{B}-\sigma_{\mathrm{B}}^{2} / 2}}\right)=\Phi^{-1}\left(\epsilon_{t}\right) \quad \text { if } \theta_{t-1}<\theta^{*} \\
\frac{1}{\sigma_{\mathrm{B}}} \ln \left(\frac{\frac{1+g}{\theta_{t-1}}-\gamma_{t} e^{r_{\mathrm{f}}}}{\left(1-\gamma_{t}\right) e^{\mu_{B}-\sigma_{\mathrm{B}}^{2} / 2}}\right)=\Phi^{-1}\left(\epsilon_{t}\right) \quad \text { otherwise }
\end{array}\right.
\end{aligned}
$$

with $\Phi$ the cumulative normal distribution function. Hence, the asset allocation $\gamma_{t}$ at

\footnotetext{
${ }^{9}$ The inequality holds because the policy is solvent at time $t-1$, i.e., $A_{t-1}>P_{t-1}$, and the premium $\Pi_{t-1}>0$.

${ }^{10}$ In fact for $\frac{g}{\alpha}<\frac{1+g}{\theta_{t-1}}-1$ we have $\operatorname{Pr}\left[R_{t}^{\mathbb{P}}<\left(\frac{1+g}{\theta_{t-1}}-1\right) ; R_{t}^{\mathbb{P}}<\frac{g}{\alpha}\right]=\operatorname{Pr}\left(R_{t}^{\mathbb{P}}<\frac{g}{\alpha}\right)$ and we rewrite $g / \alpha<$ $\frac{1+g}{\theta_{t-1}}-1 \Longleftrightarrow \theta_{t-1}<\frac{1+g}{1+g / \alpha}=\theta^{*}$ where we need $(1+g / \alpha)>0$. In our application with $\alpha$ close to $100 \%$ and $g$ close to zero this condition is fulfilled.

${ }^{11}$ In the case where $\frac{g}{\alpha}>\frac{1+g}{\theta_{t-1}}-1$ we have $\operatorname{Pr}\left(\frac{g}{\alpha}<R_{t}^{\mathbb{P}}<\frac{1-\theta_{t-1}}{\theta_{t-1}-\alpha}\right)=0$ and $\operatorname{Pr}\left[R_{t}^{\mathbb{P}}<\left(\frac{1+g}{\theta_{t-1}}-1\right) ; R_{t}^{\mathbb{P}}<\frac{g}{\alpha}\right]=$ $\operatorname{Pr}\left(R_{t}^{\mathbb{P}}<\frac{1+g}{\theta_{t-1}}-1\right)$.
} 
C. Mirza and J. Wagner - Participating Life Insurance: Which Contracts Are Win-Win?

time $t$ is given by:

$$
\operatorname{Pr}\left(\mathbb{A}_{t}\right)=\epsilon_{t} \Longleftrightarrow \gamma_{t}= \begin{cases}\frac{e^{\mu_{B}-\sigma_{\mathrm{B}}^{2} / 2+\sigma_{\mathrm{B}} \Phi^{-1}\left(\epsilon_{t}\right)}-\frac{1-\alpha}{\theta_{t-1}-\alpha}}{e^{\mu_{B}-\sigma_{\mathrm{B}}^{2} / 2+\sigma_{\mathrm{B}} \Phi^{-1}\left(\epsilon_{t}\right)}-e^{r_{\mathrm{f}}}} & \text { if } \theta_{t-1}<\theta^{*}, \\ \frac{e^{\mu_{B}-\sigma_{\mathrm{B}}^{2} / 2+\sigma_{\mathrm{B}} \Phi^{-1}\left(\epsilon_{t}\right)}-\frac{1+g}{\theta_{t-1}}}{e^{\mu_{B}-\sigma_{\mathrm{B}}^{2} / 2+\sigma_{\mathrm{B}} \Phi^{-1}\left(\epsilon_{t}\right)}-e^{r_{\mathrm{f}}}} & \text { otherwise. }\end{cases}
$$

- Following the implementation of model (A), define the yearly asset allocations $\gamma_{t}^{i}$ in each scenario $i$ (see above). Under these allocations, consider the Monte Carlo estimate of the equity holder's net present value

$$
\widehat{N P V}\left(E_{0}\right)=\frac{1}{N} \sum_{i=1}^{N} \max \left[A_{T}^{i \mathbb{Q}}\left(E_{0}\right)-P_{T}^{i \mathbb{Q}}\left(E_{0}\right), 0\right] e^{-r_{\mathrm{f}} \cdot T}-E_{0},
$$

where we use $E_{0}=E_{0}\left(\left\{\gamma_{t}^{i}\right\}\right)$. The numerical solution of the optimal equity capital $E_{0}^{*}>0$ from (12) comes from $\widehat{N P V}\left(E_{0}^{*}\right)=0$. For calculating $E_{0}^{*}$ define a recursive formula $E_{0}^{(j)}$ of the expected equity capital at maturity $T$ discounted at $t=0$,

$$
E_{0}^{(j+1)}=\frac{1}{N} \sum_{i=1}^{N} \max \left[A_{T}^{i^{\mathbb{Q}}}\left(E_{0}^{(j)}\right)-P_{T}^{i \mathbb{Q}}\left(E_{0}^{(j)}\right), 0\right] e^{-r_{\mathrm{f}} \cdot T} .
$$

For any initial $E_{0}^{(0)} \in \mathbb{R}$ there exists a $k$ such that, $E_{0}^{(k)}=E_{0}^{(k+1)}=E_{0}^{*}$.

In the presentation of our results, we will make use of the following notations. We introduce the yearly average of asset allocation $\hat{\gamma}_{t}$,

$$
\hat{\gamma}_{t}=\frac{1}{N} \sum_{i=1}^{N} \gamma_{t, i}
$$

and the asset allocation average of the portfolio during the whole duration of the contract,

$$
\bar{\gamma}=\frac{1}{T} \sum_{t=1}^{T} \hat{\gamma}_{t}
$$




\section{Further results for model (A)}

\begin{tabular}{|c|c|c|c|c|c|c|c|c|c|c|c|}
\hline \multicolumn{4}{|c|}{ Parameters (in \%) } & \multicolumn{2}{|c|}{ Insurer } & \multicolumn{4}{|c|}{ Policyholder } & \multicolumn{2}{|c|}{ Equity holder } \\
\hline$r_{\mathrm{f}}$ & $g$ & $\alpha$ & $\epsilon$ & $E_{0}^{*}$ & $\gamma^{*}$ & $\mathbb{E}\left(L_{T}\right)$ & $\sigma\left(L_{T}\right)$ & $\operatorname{RoP}(\%)$ & $C E$ & $\mathbb{E}\left(E_{T}\right)$ & RoE (\%) \\
\hline 1.5 & 1.5 & 90 & 0.5 & 0.003 & 0.969 & 1.171 & 0.006 & 1.59 & 1.171 & 0.0114 & 15.59 \\
\hline 1.5 & 1.0 & 90 & 0.5 & 0.007 & 0.872 & 1.217 & 0.036 & 1.99 & 1.215 & 0.0258 & 13.18 \\
\hline 1.5 & 0.5 & 90 & 0.5 & 0.010 & 0.803 & 1.253 & 0.058 & 2.28 & 1.246 & 0.0343 & 13.14 \\
\hline 1.5 & 0.0 & 90 & 0.5 & 0.012 & 0.741 & 1.286 & 0.080 & 2.55 & 1.274 & 0.0418 & 13.35 \\
\hline 1.5 & -0.5 & 90 & 0.5 & 0.014 & 0.682 & 1.318 & 0.101 & 2.80 & 1.299 & 0.0490 & 13.62 \\
\hline 1.5 & -1.0 & 90 & 0.5 & 0.015 & 0.627 & 1.349 & 0.123 & 3.04 & 1.322 & 0.0560 & 13.93 \\
\hline 1.5 & -1.5 & 90 & 0.5 & 0.017 & 0.573 & 1.380 & 0.144 & 3.27 & 1.344 & 0.0629 & 14.25 \\
\hline
\end{tabular}

Table 8: Model $(A)$ - Variation of the interest rate guarantee with volatility $\sigma_{\mathrm{B}} / 2$. Compare with Table 4.

\begin{tabular}{|c|c|c|c|c|c|c|c|c|c|c|c|}
\hline \multicolumn{4}{|c|}{ Parameters (in \%) } & \multicolumn{2}{|c|}{ Insurer } & \multicolumn{4}{|c|}{ Policyholder } & \multicolumn{2}{|c|}{ Equity holder } \\
\hline$r_{\mathrm{f}}$ & $g$ & $\alpha$ & $\epsilon$ & $E_{0}^{*}$ & $\gamma^{*}$ & $\mathbb{E}\left(L_{T}\right)$ & $\sigma\left(L_{T}\right)$ & $\operatorname{RoP}(\%)$ & $C E$ & $\mathbb{E}\left(E_{T}\right)$ & RoE (\%) \\
\hline 1.5 & 1.0 & 80 & 0.5 & 0.014 & 0.792 & 1.240 & 0.050 & 2.18 & 1.235 & 0.0592 & 15.37 \\
\hline 1.5 & 1.0 & 82 & 0.5 & 0.013 & 0.809 & 1.235 & 0.047 & 2.14 & 1.231 & 0.0513 & 15.05 \\
\hline 1.5 & 1.0 & 84 & 0.5 & 0.011 & 0.826 & 1.231 & 0.044 & 2.10 & 1.227 & 0.0441 & 14.67 \\
\hline 1.5 & 1.0 & 86 & 0.5 & 0.010 & 0.842 & 1.226 & 0.041 & 2.06 & 1.223 & 0.0375 & 14.24 \\
\hline 1.5 & 1.0 & 88 & 0.5 & 0.009 & 0.857 & 1.222 & 0.038 & 2.02 & 1.219 & 0.0315 & 13.75 \\
\hline 1.5 & 1.0 & 90 & 0.5 & 0.007 & 0.872 & 1.217 & 0.036 & 1.99 & 1.215 & 0.0258 & 13.18 \\
\hline 1.5 & 1.0 & 92 & 0.5 & 0.006 & 0.887 & 1.213 & 0.033 & 1.95 & 1.210 & 0.0206 & 12.49 \\
\hline 1.5 & 1.0 & 94 & 0.5 & 0.005 & 0.901 & 1.208 & 0.029 & 1.91 & 1.206 & 0.0156 & 11.64 \\
\hline 1.5 & 1.0 & 96 & 0.5 & 0.004 & 0.917 & 1.202 & 0.026 & 1.86 & 1.201 & 0.0109 & 10.49 \\
\hline 1.5 & 1.0 & 98 & 0.5 & 0.003 & 0.934 & 1.195 & 0.021 & 1.80 & 1.194 & 0.0062 & 8.61 \\
\hline 1.5 & 1.0 & 99 & 0.5 & 0.002 & 0.945 & 1.191 & 0.018 & 1.76 & 1.190 & 0.0037 & 7.06 \\
\hline
\end{tabular}

Table 9: Model (A) - Variation of the policyholder participation rate with volatility $\sigma_{\mathrm{B}} / 2$. Compare with Table 5 . 


\section{Detailed results for model (B)}

\begin{tabular}{|c|c|c|c|c|c|c|c|c|c|c|c|}
\hline \multicolumn{4}{|c|}{ Parameters (in \%) } & \multicolumn{2}{|c|}{ Insurer } & \multicolumn{4}{|c|}{ Policyholder } & \multicolumn{2}{|c|}{ Equity holder } \\
\hline$r_{\mathrm{f}}$ & $g$ & $\alpha$ & $\epsilon$ & $E_{0}^{*}$ & $\hat{\gamma}^{*}$ & $\mathbb{E}\left(L_{T}\right)$ & $\sigma$ & $\operatorname{RoP}(\%)$ & $C E$ & $\mathbb{E}\left(E_{T}\right)$ & RoE (\%) \\
\hline 2.0 & 1.0 & 90 & 0.5 & 0.089 & 0.885 & 11.592 & 1.261 & 2.668 & 11.531 & 0.180 & 7.32 \\
\hline 1.9 & 1.0 & 90 & 0.5 & 0.082 & 0.894 & 11.515 & 1.253 & 2.548 & 11.455 & 0.166 & 7.36 \\
\hline 1.8 & 1.0 & 90 & 0.5 & 0.074 & 0.903 & 11.438 & 1.245 & 2.428 & 11.379 & 0.152 & 7.41 \\
\hline 1.7 & 1.0 & 90 & 0.5 & 0.067 & 0.913 & 11.361 & 1.238 & 2.306 & 11.302 & 0.138 & 7.47 \\
\hline 1.6 & 1.0 & 90 & 0.5 & 0.060 & 0.922 & 11.284 & 1.232 & 2.188 & 11.225 & 0.124 & 7.55 \\
\hline 1.5 & 1.0 & 90 & 0.5 & 0.053 & 0.932 & 11.206 & 1.226 & 2.063 & 11.148 & 0.111 & 7.67 \\
\hline 1.4 & 1.0 & 90 & 0.5 & 0.045 & 0.942 & 11.127 & 1.221 & 1.936 & 11.070 & 0.096 & 7.82 \\
\hline 1.3 & 1.0 & 90 & 0.5 & 0.038 & 0.952 & 11.049 & 1.216 & 1.808 & 10.991 & 0.082 & 8.08 \\
\hline 1.2 & 1.0 & 90 & 0.5 & 0.030 & 0.963 & 10.969 & 1.212 & 1.677 & 10.911 & 0.067 & 8.50 \\
\hline
\end{tabular}

Table 10: Results from the sensitivity analysis in model (B) under variation of the risk-free interest rate, see Figure 10(a,b).

\begin{tabular}{|c|c|c|c|c|c|c|c|c|c|c|c|}
\hline \multicolumn{4}{|c|}{ Parameters (in \%) } & \multicolumn{2}{|c|}{ Insurer } & \multicolumn{4}{|c|}{ Policyholder } & \multicolumn{2}{|c|}{ Equity holder } \\
\hline$r_{\mathrm{f}}$ & $g$ & $\alpha$ & $\epsilon$ & $E_{0}^{*}$ & $\hat{\gamma}^{*}$ & $\mathbb{E}\left(L_{T}\right)$ & $\sigma$ & $\operatorname{RoP}(\%)$ & $C E$ & $\mathbb{E}\left(E_{T}\right)$ & $\operatorname{RoE}(\%)$ \\
\hline 1.5 & 1.2 & 90 & 0.5 & 0.041 & 0.949 & 11.172 & 1.227 & 2.009 & 11.114 & 0.091 & 8.15 \\
\hline 1.5 & 1.0 & 90 & 0.5 & 0.053 & 0.932 & 11.206 & 1.226 & 2.063 & 11.148 & 0.111 & 7.67 \\
\hline 1.5 & 0.5 & 90 & 0.5 & 0.074 & 0.897 & 11.280 & 1.228 & 2.183 & 11.221 & 0.148 & 7.25 \\
\hline 1.5 & 0.0 & 90 & 0.5 & 0.090 & 0.866 & 11.348 & 1.236 & 2.285 & 11.287 & 0.179 & 7.15 \\
\hline 1.5 & -0.5 & 90 & 0.5 & 0.103 & 0.839 & 11.413 & 1.250 & 2.389 & 11.350 & 0.206 & 7.16 \\
\hline 1.5 & -1.0 & 90 & 0.5 & 0.116 & 0.812 & 11.476 & 1.269 & 2.488 & 11.410 & 0.232 & 7.21 \\
\hline 1.5 & -1.5 & 90 & 0.5 & 0.127 & 0.787 & 11.538 & 1.293 & 2.585 & 11.468 & 0.257 & 7.28 \\
\hline
\end{tabular}

Table 11: Results from the sensitivity analysis in model (B) under variation of the interest rate guarantee, see Figure 10(c,d).

\begin{tabular}{|c|c|c|c|c|c|c|c|c|c|c|c|}
\hline \multicolumn{4}{|c|}{ Parameters (in \%) } & \multicolumn{2}{|c|}{ Insurer } & \multicolumn{4}{|c|}{ Policyholder } & \multicolumn{2}{|c|}{ Equity holder } \\
\hline$r_{\mathrm{f}}$ & $g$ & $\alpha$ & $\epsilon$ & $E_{0}^{*}$ & $\hat{\gamma}^{*}$ & $\mathbb{E}\left(L_{T}\right)$ & $\sigma$ & $\operatorname{RoP}(\%)$ & $C E$ & $\mathbb{E}\left(E_{T}\right)$ & RoE (\%) \\
\hline 1.5 & 1.0 & 84 & 0.5 & 0.071 & 0.912 & 11.219 & 1.231 & 2.084 & 11.160 & 0.166 & 8.91 \\
\hline 1.5 & 1.0 & 86 & 0.5 & 0.065 & 0.919 & 11.215 & 1.229 & 2.078 & 11.156 & 0.147 & 8.53 \\
\hline 1.5 & 1.0 & 88 & 0.5 & 0.059 & 0.925 & 11.211 & 1.227 & 2.071 & 11.152 & 0.129 & 8.12 \\
\hline 1.5 & 1.0 & 90 & 0.5 & 0.053 & 0.932 & 11.206 & 1.226 & 2.063 & 11.148 & 0.111 & 7.67 \\
\hline 1.5 & 1.0 & 92 & 0.5 & 0.046 & 0.939 & 11.200 & 1.224 & 2.054 & 11.142 & 0.092 & 7.16 \\
\hline 1.5 & 1.0 & 94 & 0.5 & 0.039 & 0.946 & 11.194 & 1.223 & 2.044 & 11.136 & 0.074 & 6.59 \\
\hline 1.5 & 1.0 & 96 & 0.5 & 0.031 & 0.954 & 11.186 & 1.223 & 2.031 & 11.128 & 0.055 & 5.89 \\
\hline 1.5 & 1.0 & 98 & 0.5 & 0.021 & 0.964 & 11.175 & 1.222 & 2.013 & 11.117 & 0.034 & 4.93 \\
\hline
\end{tabular}

Table 12: Results from the sensitivity analysis in model (B) under variation of the policyholder participation rate, see Figure 10(e,f). 
C. Mirza and J. Wagner - Participating Life Insurance: Which Contracts Are Win-Win?

\begin{tabular}{|c|c|c|c|c|c|c|c|c|c|c|c|}
\hline \multicolumn{4}{|c|}{ Parameters (in \%) } & \multicolumn{2}{|c|}{ Insurer } & \multicolumn{4}{|c|}{ Policyholder } & \multicolumn{2}{|c|}{ Equity holder } \\
\hline$r_{\mathrm{f}}$ & $g$ & $\alpha$ & $\epsilon$ & $E_{0}^{*}$ & $\hat{\gamma}^{*}$ & $\mathbb{E}\left(L_{T}\right)$ & $\sigma$ & $R o P(\%)$ & $C E$ & $\mathbb{E}\left(E_{T}\right)$ & $\operatorname{RoE}(\%)$ \\
\hline$\overline{1.5}$ & 1.0 & 90 & 1.00 & 0.044 & 0.934 & 11.431 & 1.688 & 2.417 & 11.320 & 0.098 & 8.32 \\
\hline 1.5 & 1.0 & 90 & 0.50 & 0.053 & 0.932 & 11.206 & 1.226 & 2.063 & 11.148 & 0.111 & 7.67 \\
\hline 1.5 & 1.0 & 90 & 0.20 & 0.063 & 0.930 & 11.069 & 0.798 & 1.841 & 11.044 & 0.124 & 7.02 \\
\hline 1.5 & 1.0 & 90 & 0.10 & 0.069 & 0.930 & 11.020 & 0.563 & 1.760 & 11.007 & 0.132 & 6.65 \\
\hline 1.5 & 1.0 & 90 & 0.05 & 0.075 & 0.929 & 10.998 & 0.419 & 1.724 & 10.991 & 0.140 & 6.35 \\
\hline 1.5 & 1.0 & 90 & 0.02 & 0.083 & 0.928 & 10.985 & 0.300 & 1.704 & 10.982 & 0.148 & 6.03 \\
\hline 1.5 & 1.0 & 90 & 0.01 & 0.088 & 0.928 & 10.981 & 0.243 & 1.696 & 10.978 & 0.154 & 5.83 \\
\hline
\end{tabular}

Table 13: Results from the sensitivity analysis in model (B) under variation of the safety level, see Figure 10(g,h). 